\title{
Imperfect Information Transmission from Banks to Investors: Macroeconomic Implications
}

\author{
Nicolás Figueroa, Oksana Leukhina, Carlos Ramírez*
}

September, 2018

\begin{abstract}
We study the interaction of information transmission in loan-backed asset markets and screening effort in a general equilibrium framework. Originating banks can screen their borrowers, but can inform investors of their asset type only through an error-prone rating technology. The premium paid on highly rated assets emerges as the main determinant of screening effort. Because the rating technology is imperfect, this premium is insufficient to induce the efficient level of screening. However, the fact that banks know their asset quality and produce public information accordingly helps keep the premium high. Mandatory rating and mandatory ratings disclosure policies interfere with this decision margin, thereby reducing informativeness of high ratings, lowering the premium paid on them, and exacerbating the credit misallocation problem. Policies that work to increase accuracy and/or cost of rating technology can help restore efficiency. If, as in Skreta and Veldkamp (2009), we associate the expansion leading up to the recent financial crisis with declining rating accuracy, our model helps interpret several puzzling pre-crisis observations: laxer screening effort, intensified rating activity, ratings inflation, the decline in the premium paid on highly rated assets, and rising prevalence of triple-A ratings. The same model mechanism also helps explain the variation in default rates across asset classes documented in Cornaggia, Cornaggia, and Hund (2017).
\end{abstract}

JEL Codes: G01, G24, G28

Keywords: credit misallocation, information asymmetry, information production, screening effort, rising asset complexity, mandatory rating, mandatory ratings disclosure

* Nicolas Figueroa: Instituto de Economía, Pontificia Universidad Católica de Chile; Oksana Leukhina: Federal Reserve Bank of St. Louis; Carlos Ramírez: Federal Reserve Board 
Acknowledgements: We would like to thank Hengjie Ai, Anmol Bhandari, Philip Bond, Theo Eicher, Mark Flannery, Kristopher Gerardi, Jonathan Heathcote, Burton Hollifield, Markus Opp, Uday Rajan, William Roberds, Bryan Routledge, Chester Spatt, Venky Venkateswaran and the seminar participants at the University of Washington, Pontificia Universidad Católica de Chile, the Federal Reserve Bank of Atlanta, the Federal Reserve Bank of Minneapolis, the 2014 Midwest Macro Conference, the 2014 Midwest Economics Association Conference, the 2014 North American Meetings of the Econometric Society and the 2015 Carnegie Mellon University Conference entitled "The Economics of Credit Rating Agencies, Credit Ratings and Information Intermediaries." 


\section{Introduction}

The five year economic expansion leading up to the 2007-2008 financial crisis witnessed an unprecedented growth of markets for securitized products. The ten-fold growth in the annual issue of loan-backed assets accounts for roughly half of this expansion, and it will be the focus of this paper for concreteness [Bord and Santos (2015)]. ${ }^{1}$ Several empirical papers, e.g. Purnanandam (2011), Keys, Mukherjee, Seru, and Vig (2010), Keys, Seru, and Vig (2012), Bord and Santos (2015), Rajan, Seru, and Vig (2018), suggested that the rise of securitization directly contributed to laxer screening standards observed prior to the crisis, lending support to economists' public opinion regarding the adverse consequences of securitization on the originators' incentives to screen their borrowers [Stiglitz (2007), Blinder (2007)]. ${ }^{2}$

Nonetheless, our theoretical understanding of real implications of markets for loan-backed assets remains limited [Gorton and Metrick (2011)]. We defer to the large body of literature, exemplified by Gorton and Pennacchi (1995) and Parlour and Plantin (2008), to explain the rise of these markets. ${ }^{3}$ We simply assume their existence and study macroeconomic implications of information asymmetry that plagues these market. ${ }^{4}$ Our main premise is that banks, whose screening choices determine resource allocation in the economy, possess valuable information regarding their asset quality which is not available to investors, who provide the funds and bear the risk. Our specific goal is to elucidate the interaction of strategic information production by way of ratings and ratings' disclosures on the part of banks and their screening effort at the time of loan origination.

To this end, we develop a general equilibrium rational expectations framework with heterogeneous borrowers, heterogeneous banks, and representative investors. In order to raise funds, banks must sell their baskets of loans to investors. Consistent with the classic role of intermediaries, banks are able to make sure, at a cost, that they extend a high quality loan basket. The information available to banks about their asset is not observable by investors, but an imperfect rating technology, which reveals the true asset type with a fixed probability, is available to banks at a cost. Profit maximizing banks choose their screening effort, whether or not to rate their asset and whether or not to disclose the ratings. Employing the rating technology should be interpreted loosely as engaging in a costly process, which results, with some positive probability, in the enhancement of the perceived value of the asset. Such process may involve hiring consultants to navigate the rating process and shopping for a favorable rating. (We will loosely refer to the uptake of rating technology among originating banks as the intensity of ratings shopping. $\left.{ }^{5}\right)$ Investors observe the disclosed ratings and pay competitive prices in line with rational expectations regarding asset quality.

Our assumptions of information asymmetry and strategic use/disclosure of error-prone ratings are well grounded in the data. ${ }^{6}$ Indeed, Benmelech and Dlugosz (2009a) employ tranche-level CLO (Collateralized

\footnotetext{
${ }^{1}$ While we focus on loan-backed assets for concreteness, the insights extend to markets for securities backed by corporate debt, provided that banks involved in debt underwriting and issue of securities act as middlemen between private firms and investors (pension funds, college endowment funds, etc), performing the important service of screening and obtaining ratings.

${ }^{2}$ Purnanandam (2011) uncovers that banks with greater involvement in secondary markets originated lower quality mortgages. Keys, Mukherjee, Seru, and Vig (2010) and Keys, Seru, and Vig (2012) explore loan variation to borrowers with the credit score around 620 , i.e. threshold commonly used in securitization. They find that $620+$ loans default at the rate $10-25 \%$ above that of the 620- loans. Mian and Sufi (2009) provide corroborating evidence from zip-code level data on subprime lending. Bord and Santos (2015) find that loans sold to CLOs at the time of issue are more likely to default. The evidence provided in Rajan, Seru, and Vig (2018) strongly suggests that standards were loosened along the soft information dimension.

${ }^{3}$ The challenge for this literature is to reconcile loan sales with the classic role of intermediaries discussed in Boyd and Prescott (1986) and Holmstrom and Tirole (1997). This literature largely agrees on liquidity needs as underlying loan sales. Building on these insights, we simply assume that none of the banks in the model have any funds and must raise them through loan sales.

${ }^{4}$ Gorton (2009) points out the severity of asymmetric information due to the loss of information about the quality of the underlying loans during the securitization process. Beltran, Cordell, and Thomas (2017) argue this type of information asymmetry was severe enough to cause the collapse of the ABS CDOs market.

${ }^{5}$ We have also worked out a model with multiple ratings draws as is typically done in credit ratings literature (e.g. Skreta and Veldkamp (2009)) but did not find additional insight sufficient to justify the added complexity.

${ }^{6}$ In the case of absent liquidity needs, the problem of information asymmetry between banks and investors could theoretically
} 
Loan Obligations) data to show that there is a significant mismatch between tranche ratings and the quality of underlying collateral. They also document that $70 \%$ of the dollar value of CLO tranches received a triple-A rating in 2000 , while $23 \%$ did not have a published rating.

We employ our framework to describe the interaction of intermediaries' strategic information production in the face of uncertain ratings with asset prices and resource allocation. We intentionally abstract from modeling rating agencies and their strategic behavior, instead assuming a simple unbiased but error-prone rating technology. This modeling choice allows us to isolate a specific theoretical mechanism which has not received sufficient attention in the literature. We show that this theoretical mechanism is consistent with several puzzling pre-crisis observations and that, contrary to conventional wisdom, it deems mandatory ratings and mandatory ratings disclosure policies counterproductive. The later result is due entirely to the endogeneity of information production. We proceed to detail these claims.

The following important insight immediately emerges from our model: It is the premium paid on assets with good ratings that disciplines the screening effort. Therefore, understanding what determines this premium is crucial for understanding credit allocation in the economy. Our analysis reveals that the premium paid on highly rated assets is directly proportional to an endogenous object we refer to as informativeness of a good rating, $\operatorname{Pr}_{G \mid G R}-\operatorname{Pr}_{G \mid N R}$. This quantity describes the gain in investors' rational belief that the asset is of high quality, which results from observing a good rating. In the case of a perfectly accurate rating technology, rating informativeness is maximal, and the constrained efficient screening effort and resource allocation are attained. This result is due to the fact that asset issuers know the quality of their asset, and their rating behavior reflects this information. However, an imperfect rating technology lowers the informational content of a good rating, both directly, by providing a less accurate signal, and indirectly, by encouraging some sellers of poor quality assets to try their luck at getting a good rating. As a result, the link between high ratings and asset quality weakens (i.e. ratings inflation) and the premium paid on highly rated assets falls to a level insufficient to induce the constrained efficient level of screening. In general, an intensified use of a rating technology among the sellers of poor quality assets (i.e. intensified ratings shopping) weakens the screening activity in the economy.

The model mechanism is consistent with several puzzling observations of the expansionary period preceding the 2008 crisis. Following Skreta and Veldkamp (2009), we associate this period with a decline in ratings' accuracy, as it reflects a well-documented growing trend in asset complexity. ${ }^{7}$ In the context of our model, a decrease in rating technology precision unambiguously reduces the level of screening effort at the stage of loan origination thereby exacerbating the degree of resource misallocation. Therefore, first and foremost, the model helps us interpret the observations that laxer screening standards were applied in the expansionary period leading up to the crisis and loan delinquency rates exploded beginning with 2007. ${ }^{8}$ Although the practice of applying looser screening standards in economic booms is widely documented [see Asea and Blomberg (1998), Berger and Udell (2004), Lown and Morgan (2006), Rajan (1994)], it seems to have been exacerbated by the rise of secondary markets [see Purnanandam (2011), Keys, Mukherjee, Seru, and Vig (2010), Keys, Seru, and

be resolved if originating banks retained the most risky (junior) tranche of their loan basket, thereby sending a credible signal to asset buyers (e.g. DeMarzo (2005)). In practice, however, retention of a junior tranche is often combined with shorting of a senior tranche which weakens the signal. In fact, Beltran, Cordell, and Thomas (2017) documents that it is more common for asset issuers to retain senior tranches. Nonetheless, we have also worked out a version of our model in which banks are required to hold a positive fraction of their assets. None of the results changed.

${ }^{7}$ As explained above, we intentionally abstract from modeling rating agencies. However, any changes in rating agencies' behavior that effectively increase ratings uncertainty may be thought of as reinforcing the declining trend in ratings accuracy due to rising asset complexity.

${ }^{8}$ The upsurge in loan delinquency rates can be seen in aggregate data compiled by the Federal Financial Institutions Examination Council (Reports of Condition and Income for all Insured U.S. Commercial Banks) and retrieved from https://fred.stlouisfed.org/series. 
Vig (2012), Bord and Santos (2015), Rajan, Seru, and Vig (2018)]. ${ }^{9}$ Rising collateral (e.g. housing) values are also characteristic of the expansion that preceded the recent crisis. In the context of our model, this would mean rising loan payoffs and hence a further decline of screening effort.

Our focus is on the decline in ratings' accuracy. The direct implication of a lower ratings' accuracy is that it reduces informativeness of a good rating. Because mistakes are more likely to happen, this effect is further amplified via the intensified strategic ratings of poor quality assets. This amplification effect makes a qualitative difference. It makes it possible for the prevalence of highly rated traded assets to rise despite the declining quality of extended loans. The premium paid on loan baskets with good ratings falls (i.e. the spread between high yield and low yield assets declines), thereby relaxing the incentives for loan screening at origination and exacerbating the resource misallocation problem. Therefore, a drop in the accuracy of ratings, when viewed in the context of our model, helps us interpret additional puzzling features of the pre-crisis period - an intensified rating activity, ratings inflation, and a drop in the premium paid on highly rated assets, and increased prevalence of triple-A rated assets despite the worsening pool of loans to back them.

Benmelech and Dlugosz (2009b) and Griffin and Tang (2011) provide empirical evidence for the intensified rating activity and ratings inflation prior to the crisis. The historically low premium on highly rated assets is simply an upshot of ratings inflation. Nonetheless, to provide further evidence of this fact, we compiled a panel, tranche-level, dataset on securities backed by small business loans (Source: ABSnet). ${ }^{10}$ The time series of the ratio of the yield on non-triple-A tranches and tranches with at least one triple-A rating is reported in Figure 1. Clearly, the yield differential falls dramatically throughout the expansion preceding the financial crisis of August 2008, indicating a drop in the premium paid on highly rated assets. Our explanation for this trend emphasizes the endogenous decline in the informativeness of good ratings reflected in market prices. Finally, the rise in prevalence of triple-A ratings is driven by the upsurge in issue of securitized products, the majority of which carried the best rating and later resulted in massive downgrades. ${ }^{11}$

The same model mechanism also helps us interpret the variation in ratings inflation across asset classes, documented in Cornaggia, Cornaggia, and Hund (2017), where it is found that, controlling for initial ratings, the more opaque asset classes (such as CDOs) exhibit greater default rates. ${ }^{12}$ As suggested in Cornaggia, Cornaggia, and Hund (2017), the more opaque asset classes entail a lower rating precision thereby encouraging rating activity and resulting in less meaningful ratings. This mechanism appears in Skreta and Veldkamp (2009) and in our model. Our model helps drive this point further by emphasizing the incentive to apply looser lending standards to loans used to create more complicated securities. This effect also contributes to raising default probability (conditional on any given rating).

At the center of our analysis are two regulatory policies proposed by the U.S. Securities and Exchange Commission, namely, mandatory rating and mandatory ratings disclosure. Contrary to conventional wisdom, we find both policies to be counterproductive. Both policies worsen the degree of credit misallocation in the economy. Importantly, this result stems from the presence of a feedback effect from financial markets on aggregate activity, which has not been explored in related literature on information production in financial

\footnotetext{
${ }^{9}$ Rajan, Seru, and Vig (2018) show the ability of loan interest rates to explain the variation in default rates has declined, which strongly suggests that lending standards were loosened along the soft information dimension.

${ }^{10}$ The borrowers' soft information aquisition that motivates our setup seems to be most relevant in the case of small business borrowers, which explains our choice of this type of asset backed securities. Small firms are usually informationally opaque, lacking audited financial statements, thereby making the assessment of their ability to repay non-trivial.

${ }^{11}$ Cornaggia, Cornaggia, and Hund (2017) and Benmelech and Dlugosz (2009b) describe ratings and evolution of securitized products.

${ }^{12}$ Mathis, McAndrews, and Rochet (2009) explain this correlation by noting that rating agencies' reputational costs depend on opaqueness of rated assets. Opp, Opp, and Harris (2013) emphasize that regulatory costs associated with ratings also differ across these asset classes.
} 
markets as it typically assumes an exogenously given distribution of asset quality. ${ }^{13}$

Under the policy of mandatory rating, rating activity on the part of sellers of low quality assets is intensified, thereby reducing informativeness of a good rating. In turn, the premium paid on assets with good ratings declines, discouraging screening effort at the stage of loan origination and further exacerbating resource misallocation. Under the policy of mandatory ratings disclosure, but voluntary rating, sellers of low quality assets are encouraged to rate their assets, as the lack of an observable rating can no longer be passed off as an undisclosed false rating. Good and bad ratings both gain signaling value. Therefore, strategic rating intensifies, thereby reducing informational value of a good rating, lowering the expected return to screening, and compounding resource misallocation in the economy. Note the strategic rating decision is crucial for the effects of policy evaluation.

Our analysis suggests that policy design aimed at raising rating accuracy (through regulation of asset complexity or oversight of rating agencies) and increasing the effective cost of ratings can help induce the efficient level of screening. Intuitively, such policy would discourage low quality asset issuers from ratings shopping, thereby raising the signaling value of high ratings and premia paid on highly rated assets. In turn, greater premia paid on highly rated assets encourage more screening at the time of loan origination. Our findings warn us against the the commonly used practice where the issuer pays for published ratings only - such a system does nothing to discourage frivolous ratings. More generally, our work emphasizes the importance of studying the incentive problems of rating agencies and alternative ways of information production [e.g. Damiano, Li, and Suen (2008), Bolton, Freixas, and Shapiro (2012), Kashyap and Kovrijnykh (2016), Goldstein and Huang (2018), Cohn, Rajan, and Strobl (2018)].

Our policy results are broadly related to the large literature dating back to Hirshleifer (1971) that studies unintended consequences of information disclosure policies in environments different from ours, where it is often shown that more information reduces welfare. To give a few examples of financial market applications, in Kurlat and Veldkamp (2015), information disclosure policy improves capital allocation but hurts investors. In Povel, Singh, and Winton (2007), mandatory information disclosure from firms to investors generates more fraud. In Andolfatto and Martin (2013) and Dang, Gorton, and Holmstrom (2015), news shocks may reduce the value of collateral that backs tradable assets and hinder intertemporal trade.

A closely related study of the real implications of risk shifting is Allen and Gale (2000), in which banks are endowed with funds but must lend to entrepreneurs to generate returns. While the entrepreneurs make resource allocation choices, they are protected by limited liability, and thus banks are the ultimate risk bearers. As a result, entrepreneurs engage in excessive risk taking. Our study is complementary to Allen and Gale (2000), as we focus on a different margin. In our model, resource allocation is determined by banks, through their screening activity. Because banks must sell off their loans to investors, i.e. the ultimate risk bearers, they engage in suboptimal screening practices.

The rest of the paper is organized as follows. Section 1 describes the model. In Section 2, we analyze the equilibrium, its existence and uniqueness. In Section 3, we employ the model to gain insight into pre-crisis empirical trends. In Section 4, we study mandatory rating and mandatory ratings disclosure policies. We conclude in Section 5. All proofs, unless otherwise stated, appear in the appendix.

\footnotetext{
${ }^{13}$ With respect to this literature, our paper is most closely related to Skreta and Veldkamp (2009), in the sense that ratings informativeness is an endogenous object determined by the sellers' rating and disclosure choices. Skreta and Veldkamp (2009) must assume that investors are unaware of the possibility of hidden information in order to avoid unraveling of trade (see Shavell (1994)). In our model, trade does not unravel because banks are in need of investors' funds. This allows us to model rational expectations. One paper that links rating activity to endogenous asset quality is Sangiorgi and Spatt (2017). However, their setting is critically different from ours and therefore describes a different set of financial markets. Specifically, asset issuers in their model do not possess an independent screening technology and therefore both parties learn about asset quality from ratings. This distinction is critical for policy evaluation.
} 


\section{Model}

We consider an economy with investors, heterogeneous borrowers, and heterogenous banks. We model borrowers in a very general way so that our setup is applicable to any sector characterized by informationally opaque borrowers relying on bank financing. Some examples would include small businesses, startups, and first time home buyers.

Borrowers desire to borrow, investors desire to save, and banks alone have the technology to screen and identify repaying borrowers. Banks need to raise funds by selling loans to investors. ${ }^{14}$ But investors do not possess the information about the underlying quality of traded assets. The importance of studying the macroeconomic implications of this type of informational asymmetry is discussed in Gorton (2009). Our goal is to examine its implications for the allocation of loanable funds, i.e. the composition of financed borrowers.

The model period can be subdivided into three stages occurring in the following order.

1. Screening of Borrowers. Taking asset prices as given, banks choose whether or not to engage in costly screening of borrowers when originating loans or choose them at random. Upon origination, loan quality is revealed to the banks. This stage determines the composition of borrowers.

2. Rating of Assets. Banks choose whether or not to engage in costly rating of their assets, taking asset prices as given. This stage determines how much information is produced to mitigate the information asymmetry friction in asset markets.

3. Asset Trade. Banks and investors trade in competitive loan markets, where asset prices are determined.

\subsection{Borrowers}

There is a continuum of measure 1 of potential borrowers of unobserved type, each of whom seeks financing in the amount of 1 unit of funds. Potential borrowers are of unobservable type $\theta \in\{G, B\}$, represented in proportions $\mu_{0}$ and $1-\mu_{0}$, respectively. Type $\theta$ repays $W_{\theta}$ on the loan.

Assumption 1 We assume that $W_{G}>W_{B}$.

\subsection{Banks}

There is a continuum of measure 1 of profit-maximizing banks, heterogeneous in their screening cost $k \sim F[0,1]$, which is unobserved to investors. $F$ is continuous and represents the cumulative distribution function of banks' screening costs. Each bank faces its own pool of potential borrowers of types $\theta \in\{G, B\}$, in proportions $\mu_{0}$ and $1-\mu_{0}$. Banks have the option of using the screening technology at the cost $k$, which guarantees financing of a good project $(\theta=G)$. Otherwise, the borrower is chosen at random. We interpret lending to a type $\theta$ borrower very generally as standing in for extending a large basket of loans that generates $W_{\theta}$ in total proceeds. ${ }^{15}$

Once the borrower is financed, the asset type $\theta$ is revealed to the bank. This information regarding the quality of underlying loans is not available to investors. At a cost $c$, banks can employ a rating technology that reveals the true asset type with probability $r \in(0.5,1]$. Because banks holding type $G$ assets are more likely to obtain a good rating on their assets, good ratings will serve as positive signals in secondary loan markets, and assets with good ratings will sell at a premium.

${ }^{14}$ This assumption guarantees the presence of secondary markets for loans.

${ }^{15}$ This would include interest and loan repayments, and collections in case of default. 
Assumption 2 We assume that $c<W_{G}-W_{B}$.

As alluded to in the Introduction, rating an asset in our model should be interpreted as engaging in a costly process that results, with some positive probability, in the enhancement of the perceived value of the asset. Indeed, the process of obtaining a triple-A rating for a large share of one's loan basket is a costly process that involves hiring consultants to obtain better information regarding the rating process of each agency and to learn how best to decompose the loan basket into tranches, as well as ratings shopping. The assumption that $r>0.5$ simply captures the idea that banks with better assets are more likely to succeed in this process.

We also assume that bad ratings are available for free to all banks, which rules out the signaling value of poor ratings and ensures that only good ratings will be revealed. Note that when more assets get rated in our model, for a fixed distribution of issued asset types, there are more undisclosed poor ratings. We will therefore interchangeably refer to the uptake of rating technology among originating banks as "rating activity" or "ratings shopping."

Because the screening cost of originating banks is not observed by investors, it follows that asset prices will be conditioned only on the presence of a good rating. We denote prices on assets with good ratings and no ratings (or hidden poor ratings) by $P_{G R}$ and $P_{N R}$, respectively. Taking these prices as given, banks choose their screening and rating strategies to maximize their profits.

\section{Rating Strategy}

Because asset prices $P_{G R}$ and $P_{N R}$ are conditioned only on the rating signal, all banks holding an asset of a given type $\theta$ will make the same decision with respect to employing the rating technology. We allow for a mixed strategy $f_{\theta}$, which refers to the probability of employing the rating technology.

A bank that holds a type $B$ asset chooses to rate it if the expected gain in the asset price strictly exceeds the cost of using the technology. The gain is positive, $P_{G R}-P_{N R}$, only in the case of an inaccurate rating, which happens with probability $1-r$. The asset is not rated if the expected gain falls short of the cost, and the mixed strategy is possible otherwise. Formally,

$$
\begin{aligned}
& f_{B}=1 \quad(1-r)\left(P_{G R}-P_{N R}\right)>c, \\
& f_{B}=0 \quad \text { if } \quad \ldots \quad<c, \\
& \begin{array}{lll}
f_{B} \in[0,1] & \ldots & =c .
\end{array}
\end{aligned}
$$

We restrict attention to the range of parameter values, derived in Lemma 1, that ensure that it is optimal to rate high quality assets $\left(f_{G}=1\right)$, i.e. that

$$
r\left(P_{G R}-P_{N R}\right)>c
$$

holds in equilibrium. From now on, we will assume $f_{G}=1$ always holds in equilibrium.

\section{Screening Strategy}

We now turn to the screening decision. Each bank, characterized by their screening cost $k$, chooses whether or not to screen, taking the asset prices $P_{G R}$ and $P_{N R}$ and the optimal rating strategies $f_{B}$ and $f_{G}$ as given.

Denote by $R_{\theta}$ the expected return from having issued an asset of type $\theta$. Because the rating technology is always employed by banks with high quality assets, the expected return from the type $G$ asset is given in (3) . With probability $r$, the bank obtains a high rating, reveals it, and sells the asset for $P_{G R}$. With probability $1-r$, this bank obtains a poor rating, hides it, and sells the asset for $P_{N R}$. The return is reduced by the rating cost and the unit loan amount. Likewise, the expected return from having the type $B$ asset is given in (4). With probability $(1-r) f_{B}$, the bank obtains a high rating, reveals it, and sells the asset for $P_{G R}$. Otherwise, the bank sells the asset for $P_{N R}$, which happens both, in the case of the accurate rating draw and the case of 
not rating the asset. The return is reduced by the expected rating cost and the unit loan amount. Therefore,

$$
\begin{aligned}
& R_{G}=r P_{G R}+(1-r) P_{N R}-c-1, \\
& R_{B}=(1-r) f_{B} P_{G R}+\left[1-(1-r) f_{B}\right] P_{N R}-f_{B} c-1 .
\end{aligned}
$$

Banks that choose to screen finance a high quality loan basket with certainty. The ex-ante expected return for these banks is given by $R_{G}-k$. Banks that choose not to spend resources on screening draw loan baskets at random and finance high quality assets with probability $\mu_{0}$. The ex-ante expected return for these banks is given by $\mu_{0} R_{G}+\left(1-\mu_{0}\right) R_{B}$. It follows that, in order to maximize the ex-ante expected return from their investment, a bank of type $k$ should screen whenever

$$
R_{G}-k \geq \mu_{0} R_{G}+\left(1-\mu_{0}\right) R_{B}
$$

i.e. when the screening cost is sufficiently small. The marginal screener is the bank of type

$$
\bar{k}=\left(1-\mu_{0}\right)\left(R_{G}-R_{B}\right) .
$$

The more productive banks $(k \leq \bar{k})$ screen and hence introduce only high quality borrowers into the economy. The less productive banks forgo the screening process and hence introduce high quality borrowers into the economy with probability $\mu_{0}$. Recall that the distribution of banks is described by $F$, which implies that the marginal screener determines the measure of high quality borrowers in the economy:

$$
\mu=F(\bar{k})+(1-F(\bar{k})) \mu_{0} .
$$

\subsection{Investors}

Investors save by purchasing loan-backed assets in competitive markets. Because we assumed that investors have no information regarding the quality of the underlying loans or screening productivity of loan originators, investors' beliefs regarding asset quality are conditioned only on the observed ratings. We denote investors' beliefs regarding asset quality by $\operatorname{Pr}_{G \mid G R}$ and $\operatorname{Pr}_{G \mid N R}$. Our assumption of competitive markets implies that investors make zero profits, i.e. that equilibrium prices on assets with good ratings and no ratings reflect their expected returns, as perceived by investors:

$$
\begin{aligned}
& P_{G R}=W_{G} \operatorname{Pr}_{G \mid G R}+W_{B}\left[1-\operatorname{Pr}_{G \mid G R}\right]=\operatorname{Pr}_{G \mid G R} \Delta W+W_{B}, \\
& P_{N R}=W_{G} \operatorname{Pr}_{G \mid N R}+W_{B}\left[1-\operatorname{Pr}_{G \mid N R}\right]=\operatorname{Pr}_{G \mid N R} \Delta W+W_{B},
\end{aligned}
$$

where $\Delta W=W_{G}-W_{B}$.

\subsection{Model Equilibrium}

We have thus far described the banks' optimal screening and rating decisions for given asset prices. We have also discussed how the asset prices are related to investors' beliefs regarding asset quality. To complete our 
definition of equilibrium, we also require that investors' beliefs are consistent with the equilibrium outcomes:

$$
\begin{aligned}
\operatorname{Pr}_{G \mid G R} & =\frac{\mu r}{\mu r+(1-\mu) f_{B}(1-r)} \\
\operatorname{Pr}_{G \mid N R} & =\frac{\mu(1-r)}{\mu(1-r)+(1-\mu)\left[\left(1-f_{B}\right)+f_{B} r\right]}
\end{aligned}
$$

$\operatorname{Pr}_{G \mid G R}$ corresponds to the actual fraction of high quality assets among the highly rated assets, i.e., among the high quality assets with accurate ratings and the poor quality assets with inaccurate ratings. Similarly, $\operatorname{Pr}_{G \mid N R}$ corresponds to the actual fraction of high quality assets among all unrated assets. We will refer to the belief differential

$$
\Delta \operatorname{Pr}:=\operatorname{Pr}_{G \mid G R}-\operatorname{Pr}_{G \mid N R}
$$

as the (good) rating informativeness, precisely because it captures the increment in the equilibrium probability that the asset is of high quality implied by an observation of a high rating. This endogenous quantity will play a critical role in generating all of our results. We can immediately see that the rating informativeness determines the premium paid on highly rated assets as well as the rating intensity.

Definition. An equilibrium is given by the marginal screener $\bar{k}^{*}$, the rating strategies $f_{G}^{*}=1$ and $f_{B}^{*}$, the measure of good borrowers in the economy $\mu^{*}$, investors' beliefs regarding asset quality conditional on the observed rating $\left\{\operatorname{Pr}_{G \mid G R}^{*}, \operatorname{Pr}_{G \mid N R}^{*}\right\}$ and asset prices conditional on the observed rating $\left\{P_{G R}^{*}, P_{N R}^{*}\right\}$ satisfying the following conditions:

1. Given the asset prices $\left\{P_{G R}^{*}, P_{N R}^{*}\right\}$, banks of type $k \leq \bar{k}^{*}$ find it optimal to screen their borrowers (i.e. the screening condition (5) is satisfied for these banks), while banks of type $k>\bar{k}^{*}$ find it optimal to select their borrowers at random (i.e. the screening condition (5) does not hold for these banks).

2. Given the asset prices $\left\{P_{G R}^{*}, P_{N R}^{*}\right\}$, banks that issued type $\theta$ assets find it optimal to rate according to $f_{\theta}^{*}$ (i.e. the rating optimality conditions (1) and (2) are satisfied).

3. Given investors' beliefs $\left\{\operatorname{Pr}_{G \mid G R}^{*}, \operatorname{Pr}_{G \mid N R}^{*}\right\}$, asset prices $\left\{P_{G R}^{*}, P_{N R}^{*}\right\}$ reflect expected returns: conditions (8) and (9) hold.

4. Investors' beliefs $\left\{\operatorname{Pr}_{G \mid G R}^{*}, \operatorname{Pr}_{G \mid N R}^{*}\right\}$ are consistent with the equilibrium outcomes: (10) and (11) hold.

5. The measure of resource allocation in the economy $\mu^{*} \in(0,1)$ is determined by the optimal screening strategies, summarized by $\bar{k}^{*}$ :

$$
\mu^{*}=F\left(\bar{k}^{*}\right)+\left(1-F\left(\bar{k}^{*}\right)\right) \mu_{0} .
$$

To the extent that borrower repayment $W_{\theta}$ is related to the borrower productivity in whatever entrepreneurial activity the borrower seeks to finance, the equilibrium object $\mu^{*}$ reflects the average productivity in the sector that relies on bank financing. In section 3.4, we derive the efficient level of screening $\bar{k}^{e f}$. In the spirit of Boyd and Prescott (1986) and Holmstrom and Tirole (1997), banks perform an important service of screening of borrowers, thereby directly affecting aggregate productivity through the credit allocation margin summarized by $\mu$. Our model allows us to analyze how the presence of information asymmetry in markets where loan-backed assets are traded affects the intermediaries' incentives to screen. 


\section{Equilibrium Characterization}

We solve for the equilibrium quantities and prices as follows. We first characterize the optimal rating strategy $f_{B}$ as a function of $\mu$, which ensures that Conditions 2-4 in the definition above hold. This is done in Lemma 1 and Corollary 1. Once the equilibrium relationship $f_{B}(\mu)$ is derived, it is straightforward to obtain beliefs and prices as functions of $\mu$ as well. Given these prices, the marginal screener $\bar{k}$ is determined in accordance with Condition 1 in the definition. Finally, the equilibrium resource allocation $\mu^{*}$ is found as a fixed point of (12) provided in Condition 5. Existence and uniqueness of the equilibrium are proved in Proposition 1.

\subsection{Rating Strategy}

We now proceed to characterize the rating strategy $f_{B}$, for a fixed $\mu$. The optimal rating strategy $f_{B}$, described in (1), depends on asset prices. In turn, asset prices depend on investors' beliefs through the zero profit conditions (8) and (9), and beliefs depend on $\mu$ and $f_{B}$ through the consistency conditions (8) and (9). Therefore, by substituting consistent beliefs into prices and prices into the rating optimality condition, we can determine the equilibrium dependence of the rating strategies $f_{B}$ on the fraction of good borrowers in the economy $\mu$.

It is first helpful to describe how the rating accuracy, $r$, and the cost of screening relative to the repayment differential,

$$
\tilde{c} \equiv \frac{c}{\Delta W},
$$

affect the rating decision. The lemma below characterizes the optimal rating strategy in the parameter space of $r$ and $\tilde{c}$ (for a fixed $\mu$ ).

Lemma 1 Rating strategies $f_{B}$ and $f_{G}$ in the space of $\tilde{c}$ and $r$ (for a fixed $\mu$ ). For a given measure of resource allocation, $\mu$, the rating strategy $f_{B}$ can be summarized as follows:

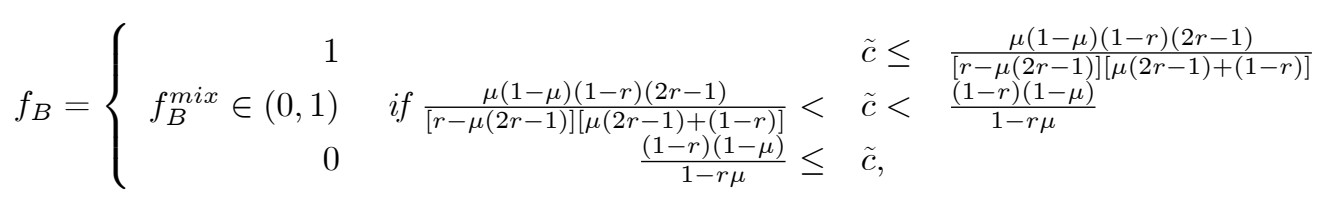

where the mixed strategy is given by $f_{B}^{m i x}=\frac{\tilde{c}(1-2 \mu r)+\mu(1-r)-\sqrt{(\tilde{c}+\mu)^{2}-\mu^{2} r(2-r)-(6-4 r) \tilde{c} r \mu}}{2 \tilde{c}(1-r)(1-\mu)} .{ }^{16}$

Moreover,

$$
f_{G}=1 \quad \text { if } \tilde{c}<\frac{r(1-\mu)}{1-r \mu} .
$$

Proof. See the appendix.

Figure 2 helps visualize this result. It illustrates the optimal rating choice for an arbitrarily chosen measure of good projects $\mu=0.5$. Recall that the asset is rated, $f_{B}>0$, whenever $(1-r) \Delta \operatorname{Pr} \geq \tilde{c}$. Higher levels of $\tilde{c}$ clearly weaken the incentive to rate poor quality assets. However, the effect of $r$ depends on its level. On one hand, raising $r$ increases rating accuracy, making it less likely that a poor quality asset obtains a lucky high rating and collects the premium. This effect discourages rating of poor quality assets. On the other hand, raising $r$ increases the rating informativeness $\Delta \operatorname{Pr}$ and the premium paid on highly rated assets. This effect tends to encourage rating activity. The latter effect dominates for low $r$. When $r$ is at its lowest, near 0.5, high ratings are largely uninformative, which implies a low premium. As a result, poor quality assets are seldom rated, despite the high likelihood of obtaining a high rating by mistake. As $r$ increases, so does the

\footnotetext{
${ }^{16}$ It is found by solving $(1-r)\left(P_{G R}-P_{N R}\right)=c$ after substituting for prices and beliefs.
} 
premium paid on high ratings, which encourages rating activity. Conversely, the former effect dominates for large values of $r$. When $r$ is near 1, the poor quality asset has no chance of obtaining a high rating and its issuer is discouraged from rating it regardless of the premium paid on high ratings. This intuition applies to the entire range of the parameter space.

Our focus on the parameter space that ensures that $f_{G}=1$ in equilibrium implies that the range of admissible $\mu$ is between 0 and

$$
\bar{\mu}:=\frac{r-\tilde{c}}{r(1-\tilde{c})},
$$

found from (15). Corollary 1 formalizes the general characterization of the equilibrium relationship $f_{B}(\mu)$ : $[0, \bar{\mu}] \rightarrow[0,1]$. We show that $f_{B}$ is 0 when $\mu=0$. It is increasing for low levels of $\mu$ and may or may not reach the level of 1 before it becomes a decreasing function of $\mu$. For sufficiently high levels of $\mu$, the rating strategy $f_{B}$ reaches the level of 0 and stays at that level as $\mu$ increases further. To understand this shape, recall the rating optimality condition (1) which reveals that the return to rating the issued asset is disciplined by the premium paid on good ratings $\left(P_{G R}-P_{N R}\right)$, which, in turn, depends on the rating informativeness $\Delta \operatorname{Pr}$. It is easy to see that $\Delta \mathrm{Pr}$ is a single-peaked function of $\mu$, increasing for small values of $\mu$ and decreasing for high values of $\mu$. The reason for this is as follows. When $\mu$ is small, there are very few good assets in the economy, so a good rating does little to change investors' beliefs regarding the asset quality. The same is true for high levels of $\mu$ when all traded assets are predominantly of high quality. For intermediate values of $\mu$ though, a good rating carries a lot of informational content. Therefore, it is for intermediate values of $\mu$ that investors are willing to pay the highest premium on good ratings and banks are most likely to try their luck at obtaining a high rating.

Corollary 1 Rating strategy $f_{B}(\mu):[0, \bar{\mu}] \rightarrow[0,1]$ as a function of resource allocation, $\mu$. If $\tilde{c}>(1-r)(2 r-1)$, then

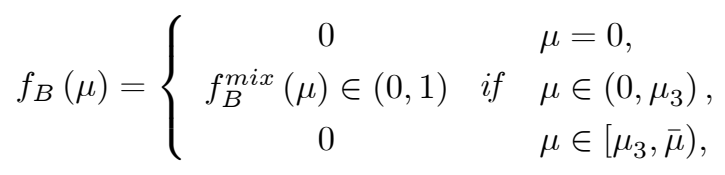

with $f_{B}$ increasing for $\mu \in\left(0, \mu_{\max }\right)$ and decreasing for $\mu \in\left(\mu_{\max }, \mu_{3}\right)$, where the constants $\mu_{\max }$ and $\mu_{3}$ are defined as

$$
\mu_{\max }=\frac{1}{2} \frac{(1-r)^{2}-\tilde{c}^{2}}{(1-r)^{2}-\tilde{c}(2 r-1)(1-r)}, \quad \mu_{3}=\frac{1-r-\tilde{c}}{1-r-r \tilde{c}} .
$$

If instead $\tilde{c} \leq(1-r)(2 r-1)$, then

$$
f_{B}= \begin{cases}0 & \mu=0, \\ f_{B}^{\text {mix }}(\mu) \in(0,1) & \mu \in\left(0, \mu_{1}\right) \\ 1 & \text { if } \quad \mu \in\left[\mu_{1}, \mu_{2}\right] \\ f_{B}^{\text {mix }}(\mu) \in(0,1) & \mu \in\left(\mu_{2}, \mu_{3}\right) \\ 0 & \mu \geq \mu_{3},\end{cases}
$$

with $f_{B}$ increasing for $\mu \in\left(0, \mu_{1}\right)$ and decreasing for $\mu \in\left(\mu_{2}, \mu_{3}\right)$, where the constants $\mu_{1}$ and $\mu_{2}$ are defined as

$$
\mu_{1}=\frac{1}{2}-\frac{1}{2} \sqrt{\frac{(1-r)(2 r-1)-\tilde{c}}{(2 r-1)(\tilde{c}+1-2 \tilde{c} r-r)}}, \quad \mu_{2}=\frac{1}{2}+\frac{1}{2} \sqrt{\frac{(1-r)(2 r-1)-\tilde{c}}{(2 r-1)(\tilde{c}+1-2 \tilde{c} r-r)}} .
$$


Proof. Notice that $\mu_{1}<\mu_{\max }<\mu_{2}<\mu_{3}<\bar{\mu}$. The proof follows from Lemma 1 after recognizing that $\mu_{1}$ and $\mu_{2}$ denote the lower and higher solutions of $f_{B}^{m i x}=1$, that $\mu_{3}$ solves $f_{B}^{m i x}=0$, and that $f_{B}^{m i x}$ is an inverted U-shaped function maximized at $\mu_{\max }$. If $\tilde{c}>(1-r)(2 r-1)$, the rating strategy $f_{B}^{m i x}$ never reaches the level of 1 . If instead $\tilde{c} \leq(1-r)(2 r-1)$, then $f_{B}^{m i x}$ will exceed 1 on the interval $\left(\mu_{1}, \mu_{2}\right)$, implying rating with certainty in that range.

\subsection{Screening Strategies and Resource Allocation}

Now that the equilibrium relationship $f_{B}(\mu)$ is characterized in Corollary 1, it is straightforward to obtain the equilibrium dependence of investors' beliefs and prices on $\mu$. Given these prices, the marginal screener $\bar{k}(\mu)$ is determined according to $(6)$ :

$$
\bar{k}(\mu)=\left(1-\mu_{0}\right) \Delta R(\mu)
$$

where the return differential is given by

$$
\begin{aligned}
\Delta R(\mu) & :=R_{G}(\mu)-R_{B}(\mu) \\
= & \left(P_{G R}(\mu)-P_{N R}(\mu)\right)\left[r-(1-r) f_{B}(\mu)\right]-\left(1-f_{B}(\mu)\right) c \\
= & \Delta W \Delta \operatorname{Pr}(\mu)\left[r-(1-r) f_{B}(\mu)\right]-\left(1-f_{B}(\mu)\right) c .
\end{aligned}
$$

An important insight emerges. It is the price differential on assets with good ratings and assets with no ratings that disciplines the banks' screening effort at the stage of loan origination. In turn, as seen from the above, this premium is proportional to the rating informativeness $\Delta \operatorname{Pr}(\mu)$ :

$$
\Delta \operatorname{Pr}(\mu)=\frac{\mu r}{\mu r+(1-\mu) f_{B}(\mu)(1-r)}-\frac{\mu(1-r)}{\mu(1-r)+(1-\mu)\left[\left(1-f_{B}(\mu)\right)+f_{B}(\mu) r\right]},
$$

obtained by substituting for the beliefs from (10) and (11). Rating informativeness is high when the rating technology is accurate and poor quality assets are not rated. In that case, a good rating implies a large gain in the perceived quality of the asset, investors pay a large premium on assets with high ratings, and more banks screen their borrowers. In the next subsection, we will show that as long as the rating technology is prone to error $(r<1)$, rating intensity confuses the market and rating informativeness is insufficient to imply the first best allocation. However, as long as the rating technology is prone to error, good ratings will not be sufficiently informative to induce the optimal level of screening effort.

Nonetheless, it is important to emphasize that the fact that $f_{B}(\mu)<1$ for a large range of admissible $\mu$ is important in generating an additional wedge between $\operatorname{Pr}_{G \mid G R}$ and $\operatorname{Pr}_{G \mid N R}$. The wedge already exists even in the case of $f_{B}(\mu)=1$ because $r>0.5$, but it is larger when $f_{B}(\mu)<1$. In other words, asset issuers know the quality of their asset and this information is reflected in their rating behavior. Less frequent rating of poor quality assets strengthens informativeness of good ratings and raises the premium paid on highly rated assets. This, in turn, encourages the screening effort. We discuss in Section 4 that policies that have been officially proposed to combat the informational asymmetry friction in asset markets are likely to be counterproductive exactly because they eliminate this endogenous wedge, thereby weakening informativeness of good ratings.

Substituting the marginal screener expression (18) into the final equilibrium condition (12), it becomes clear that the resource allocation in the economy $\mu^{*}$ can be obtained as a fixed point of

$$
\mu=F(\bar{k}(\mu))+\left[1-F(\bar{k}(\mu)] \mu_{0} .\right.
$$


To prove existence and uniqueness of equilibrium, it suffices to show that there is a unique solution $\mu^{*}$ to the above equation. The proof is formalized in Proposition 1.

The remaining equilibrium quantities and prices have already been characterized as functions of $\mu$. The equilibrium rating strategy $f_{B}^{*}$ can be determined from (14). Using this information, investors' beliefs $\left\{\operatorname{Pr}_{G \mid G R}^{*}\right.$, $\left.\operatorname{Pr}_{G \mid N R}^{*}\right\}$ are computed from consistency conditions (10) and (11). Given those, asset prices are computed from the zero profit conditions (8) and (9).

\section{Proposition 1 Existence and uniqueness of equilibrium}

Denote the right hand side of the equilibrium condition (12) by $H:\left[0, \frac{r(1-\mu)}{1-r \mu}\right] \rightarrow\left[\mu_{0}, 1\right]$,

$$
H(\mu):=F(\bar{k}(\mu))+\left[1-F(\bar{k}(\mu)] \mu_{0} .\right.
$$

Assume $\mu_{0}<\bar{\mu}$. If parameter values satisfy $\tilde{c} \leq(1-r)(2 r-1)$, then also assume

$$
\bar{f}\left(1-\mu_{0}\right)^{2} \Delta W \frac{(2 r-1)^{2}}{r(1-r)} \sqrt{\frac{1-r-\tilde{c} /(2 r-1)}{1-r-\tilde{c}(2 r-1)}} /\left(\frac{1-r}{1-r-\tilde{c}(2 r-1)}\right)^{2}<1,
$$

where $\bar{f}:=\sup _{k \in[0,1]} F^{\prime}(k)$.

Then $H^{\prime}(\mu) \leq 1$ and there exists a unique equilibrium.

Proof. See the appendix.

Note that the condition (23) imposed to ensure uniqueness is quite weak. In fact, this condition is not needed for parameterizations that imply that the equilibrium measure of high quality assets is over a half. ${ }^{17}$

\subsection{Inefficiency of the Decentralized Equilibrium Outcomes}

It is instructive to compare outcomes in the decentralized economy to the constrained efficient outcomes. In order to define the constrained efficient allocation, however, we need to specify a few more details about the production structure of the economy. For simplicity, we assume that the rating cost $c$ is simply a transfer from banks to rating agencies. We also assume that there are no additional costs associated with production of projects underlying the loan baskets, apart from the unit of funds extended. Suppose further that extending a loan basket of type $G$ results in output production in the amount of $Y_{G}$, whereas extending a loan basket of type $B$ results in output production in the amount of $Y_{B}$, where $Y_{G}>Y_{B}$. Finally, we note that the relationship between the repayment amounts and the actual output levels will satisfy $W_{G}-W_{B} \leq Y_{G}-Y_{B} \cdot{ }^{18}$

It follows that the total output of the economy is a function of the level of screening activity $\bar{k}$ :

$$
Y=F(\bar{k}) Y_{G}+(1-F(\bar{k}))\left(\mu_{0} Y_{G}+\left(1-\mu_{0}\right) Y_{B}\right)-\int_{0}^{\bar{k}} k d F(k)-1 .
$$

The first two terms give the output of the final good produced by projects underlying the loan baskets; the last two terms represent inputs involved in screening and production of projects. With a greater $\bar{k}$, more resources are used up in screening, but the unit of funds employed in production yields more output.

\footnotetext{
${ }^{17}$ We show that $H(\mu)$ is weakly decreasing for $\mu \in(0.5, \bar{\mu})$ without any restriction on parameter values.

${ }^{18}$ This relationship is consistent with either debt or equity financing contracts. Modeling the bank contracts in more detail is outside the scope of this paper and irrelevant for our analysis.
} 
The constrained efficient allocation is given by the screening activity $\bar{k}$ that maximizes $Y$. The social marginal gain of screening by any bank is $\left(1-\mu_{0}\right)\left(Y_{G}-Y_{B}\right)$, because the good borrowers are financed with probability $\mu_{0}$ even if the bank chooses not to incur the screening cost. The marginal cost for a given bank is $k$. Therefore, it is socially optimal for a bank with the screening cost $k$ to screen whenever $\left(1-\mu_{0}\right)\left(Y_{G}-Y_{B}\right)>k$. The most productive bank faces the screening $\operatorname{cost} k=0$; therefore, it is always efficient for this bank to screen. The least productive bank faces the screening cost of 1 . If $\left(1-\mu_{0}\right)\left(Y_{G}-Y_{B}\right)>1$, then even the least productive bank should screen, and so should the rest of the banks. Otherwise, there exists a cutoff marginal screener $\bar{k}^{e f} \in(0,1)$ satisfying $\bar{k}^{e f}=\left(1-\mu_{0}\right)\left(Y_{G}-Y_{B}\right)$. Formally, the socially efficient marginal screener is given by

$$
\bar{k}^{e f}=\min \left\{\left(1-\mu_{0}\right)\left(Y_{G}-Y_{B}\right), 1\right\}
$$

and the implied socially efficient measure of resource allocation is given by

$$
\mu^{e f}=F\left(\bar{k}^{e f}\right)+\left[1-F\left(\bar{k}^{e f}\right)\right] \mu_{0} .
$$

In the decentralized economy, $\bar{k}<1$, i.e. it is never the case that all banks screen. If this were the case, consistent beliefs would imply that all assets are of high quality and all assets would trade for $W_{G}$. This, in turn, would imply that no individual bank would have an incentive to engage in screening, which leads to a contradiction.

Even if $\bar{k}^{e f}<1$, the level of screening in the decentralized economy falls short of the socially efficient level, as long as $r<1$. The inutition is as follows. As long as there is room for mistakes, some issuers of low quality assets will try their luck at getting a high rating along with issuers of high quality assets. This reduces the signaling value of a high rating and hence the premium paid on highly rated assets. This low premium coupled with the reduced certainty of getting a high rating on a high quality asset discourages screening effort at the stage of loan origination. The following proposition formalizes this result.

Proposition 2 Decentralized Outcomes vs. Constrained Efficient Outcomes

Whenever $r<1$, the equilibrium level of screening activity is less than efficient and resources are misallocated:

$$
\bar{k}^{*}<\bar{k}^{e f} \text { and } \mu^{*}<\mu^{e f} \text {. }
$$

Proof. First consider the case where $\left(1-\mu_{0}\right)\left(Y_{G}-Y_{B}\right) \geq 1$ and so $\bar{k}^{e f}=1$. We want to show that $\bar{k}^{*}<\bar{k}^{e f}=1$. Suppose not. If $\bar{k}^{*}=1$ then $\mu^{*}=1$, and it follows that $P_{G R}\left(\mu^{*}\right)=P_{N R}\left(\mu^{*}\right)=W_{G}$. This, in turn, implies that no bank will choose to engage in costly screening, i.e. $\bar{k}^{*}=0$. We arrive at a contradiction.

Now consider the case where $\left(1-\mu_{0}\right)\left(Y_{G}-Y_{B}\right)<1$ and so $\bar{k}^{e f}=\left(1-\mu_{0}\right)\left(Y_{G}-Y_{B}\right)$. Drawing on equilibrium conditions (18) and (19), we have

$$
\begin{aligned}
\bar{k}^{*} & =\left(1-\mu_{0}\right) \Delta R(\mu) \\
& =\left(1-\mu_{0}\right)\left(\Delta W \Delta \operatorname{Pr}^{*}\left[r-(1-r) f_{B}^{*}\right]-\left(1-f_{B}^{*}\right) c\right) \\
& <\left(1-\mu_{0}\right) \Delta W r \Delta \operatorname{Pr}^{*}<\left(1-\mu_{0}\right) \Delta W \leq\left(1-\mu_{0}\right)\left(Y_{G}-Y_{B}\right)=\bar{k}^{e f},
\end{aligned}
$$

where the inequalities are due to $r<1$ and $\Delta \operatorname{Pr}^{*}<1$ (which follows from $(21)$ after substituting for $r<1$ ).

Recognizing that $H(\mu)$ increases in $\bar{k}$, the result that $\mu^{*}<\mu^{e f}$ follows immediately from (21) and (26).

The equilibrium level of screening effort is maximized at $r=1$. This is implied by Lemma 2 presented below, which shows that both screening effort and the average quality of projects introduced to the economy increase in $r$. In the case of $r=1$, equilibrium outcomes are efficient if loan contracts are consistent with 
$\Delta W=Y_{G}-Y_{B}$ and $c$ is treated as a resource cost.

\subsection{Macroeconomic Effects of Increasing Asset Complexity and Collateral Values}

The declining accuracy of ratings $(r \downarrow)$ is highly characteristic of the expansionary period that preceded the 2008 crisis as it reflects a well-documented trend in growing asset complexity; it will be the focus of our discussion. However, rising collateral values associated with the housing boom also characterized this period. We interpret the rise in collateral values as a decline in $\Delta W$, because more value is recovered from defaulting borrowers in the case of higher collateral prices. In this section, we show that both of these changes exacerbate the resource misallocation in the economy and explore their additional implications for pre-crisis observations. We also investigate the effects of an improvement in the pool of projects/borrowers $\left(\mu_{0} \uparrow\right)$, which may reflect the expansionary rise in the average productivity of borrowers.

Recall our measure of rating informativeness given in (20). It decreases in rating intensity, i.e. $\frac{\partial \Delta f_{B}}{\partial f_{B}}<0$. Intuitively, as more poor quality assets are rated, the probability that a good rating indicates a good asset

declines. It is also easy to see that rating informativeness increases in $r$, i.e. $\frac{\partial \Delta \mathrm{Pr}}{\partial r}>0$. Intuitively, a more precise rating technology increases the gain in the perceived quality of highly rated assets.

The level of rating informativeness is critical for the screening decision of individual banks, and therefore for the measure of resource allocation in the economy. Ceteris paribus, an increase in rating informativeness leads to an increase in the screening activity of banks.

We proceed to derive the partial effects of various parameters on the equilibrium level of resource allocation $\mu^{*}$. It is helpful to first recall that, in any equilibrium with $f_{B}\left(\mu^{*}\right) \in(0,1)$, the issuers of poor quality assets are indifferent between rating and not rating their asset:

$$
\Delta \operatorname{Pr}=\frac{c}{\Delta W(1-r)} .
$$

It follows immediately from the above equality that (i) rating informativeness decreases in $\Delta W$ and (ii) rating informativeness increases in the cost of screening $c$ and rating accuracy $r$. The intuition for these results invokes the strategic rating behavior on the part of banks that financed poor quality loan baskets. If, for example, $\Delta W$ increases, the mixed strategy will remain viable only if $f_{B}$ also increases, which would work to reduce the rating informativeness $(\Delta \mathrm{Pr})$. Therefore, in any equilibrium where banks with low quality assets play a mixed strategy, a change in the model parameter values, whether it is $c, \Delta W$ or $r$, has an important indirect effect on the rating intensity $f_{B}$ and, therefore, on rating informativeness through condition (27). This indirect effect, then, has important consequences for screening activity at the stage of loan origination. We proceed to illustrate that this strategic rating component plays a critical role in the comparative statics analysis and policy evaluation.

We begin with rising asset complexity, which was one of the main features associated with the rise in markets for securitized products. In the context of our model, rising asset complexity is reflected in the decline of a rating precision $(r \downarrow)$. New important insight emerges with respect to the effect of rising asset complexity on screening, credit allocation, ratings inflation and prevalence of high ratings.

Lemma 2 formalizes the effect of rating accuracy on screening effort and the measure of resource allocation. An increase in the rating precision directly raises $\Delta R$ (given in (19)) by increasing the probability that high quality assets will receive a good rating and sell at a premium, and by decreasing the probability that poor quality assets will receive a good rating in error and sell at a premium. This clearly encourages banks to expend resources on screening. Moreover, the premium itself also rises, further reinforcing the incentive to screen. The reason for this is that the rating informativeness increases with $r$. When $r$ is near 0.5 , good ratings are largely 
uninformative because the poor quality assets can obtain them just as well as the high quality ones. The opposite is true when $r$ is near 1.

\section{Lemma 2 Macroeconomic effects of the change in rating accuracy $\mathrm{r}$}

In equilibrium, screening effort $\bar{k}^{*}$ and measure of resource allocation $\mu^{*}$ are strictly increasing in $r$.

Proof. See the appendix.

Figure 3 illustrates the numerical experiment of lowering the rating precision. As we move along the $\mathrm{X}$-axis, $r$ falls to represent the increase in asset complexity. We observe that the strategic rating on the part of lemon holders intensifies (panel b). For a sufficiently high rating accuracy, poor quality assets are never rated, and for a low enough level of rating precision, everyone engages in rating. ${ }^{19}$ Rating informativeness, depicted in panel $\mathrm{f}$, decreases through the direct effect of ratings becoming more prone to error, which reduces the signaling value of a good rating. But in the region where a mixed strategy is played, rating informativeness, and therefore the premium paid on highly rated assets, decline faster (panel f). In this region, investors' beliefs regarding the relative quality of highly rated assets deteriorate due to both - the direct effect of less accurate ratings and the indirect effect of the intensified rating of poor quality assets. In the same region, the fraction of banks screening and the measure of high quality projects/assets in the economy decline most rapidly (panels a and c). This is not surprising, because the screening decision depends on the premium paid on highly rated assets and on the probability of obtaining a good rating, both of which decline.

Perhaps most interestingly, we observe the possibility that the measure of highly rated assets actually increases concurrently with the declining actual measure of high quality assets in the economy (panels a and e). This happens in the region of the mixed strategy. The reason for this regularity is the intensified rating behavior on the part of banks holding poor quality assets. As the rating accuracy drops and more of the asset issuers try out their luck at getting a good rating in order to sell at a premium, the measure of highly rated assets rises. Note the endogeneity of ratings is criticial for generating this result. In a model without the endogenous ratings response, the fraction of good projects and the fraction of highly rated assets both increase with $r$.

Therefore, the decline in ratings accuracy (falling $r$ ) helps rationalize several puzzling phenomena observed prior to the financial crisis:

(1) Laxer screening standards and rising default probability, as identified by the empirical papers and data discussed in the Introduction. This is reflected in our model as less screening and a greater degree of resource misallocation resulting from a decline in $r$ (panels a and $\mathrm{c}$ of Figure 3).

(2) An intensified use of ratings, or shopping for high ratings. The model produces this feature as a result of a declining $r$ which encourages more banks to try their luck at getting a high rating, which we loosely interpret as intensified ratings shopping (panel b or Figure 3).

(3) Rising default probability conditional on a high rating. This is seen in panel d of Figure 3.

(4) A decline in spreads between high yield (low rated) and investment grade (highly rated) securities, or equivalently, a drop in the premium paid for highly rated assets. This is seen in panel $\mathrm{f}$ of Figure 3 .

(5) An increased prevalence of highly rated assets (panel e of Figure 3) and despite the worsening pool of loans to back them (panel a of Figure 3).

(6) The empirical regularity documented in Cornaggia, Cornaggia, and Hund (2017): After conditioning on ratings, the more opaque asset classes exhibit greater default rates. If we suppose that the more opaque asset classes entail a lower rating precision, our model would imply these assets would be rated more intensively,

\footnotetext{
${ }^{19}$ This effect is not unambiguous. In fact, for a low enough rating precision, $r$ near 0.5 , a good rating would be largely uninformative and would induce a low premium, which would reduce the incentive to rate.
} 
resulting in lower premia on high ratings and therefore a weaker screening effort. Lower screening effort, in turn, would further increase the default probability, conditional on a high rating.

We wish to emphasize that neither of the above facts can be studied in a model of asset markets that treats the asset quality distribution as fixed. The endogeneity of the rating margin is also important for signing some of the comparative statics effects and it will be critical for policy evaluation.

The rise in collateral values associated with the housing boom also characterized the economic expansion leading up to the financial crisis. The rise in physical collateral would imply greater collections in case of borrower default, which would map into our model as an increase in $W_{B}$, or a decline in $\Delta W$. Likewise, strengthening of the relationship between the performance of the projects underlying the disbursement of funds and performance of the financial assets would also mean lower frequency of default, or higher collections in case of default, which would be reflected in our model as a decline in $\Delta W$. To understand this interpretation, note that in many environments, a switch from debt financing towards equity financing increases productivity of the underlying projects. Our model abstracts from the details of financial contracts at the stage of asset issue, therefore any development in these markets would simply be reflected in the repayment levels $W_{B}$ and $W_{G}$.

Intuitively, an increase in the repayment differential $\Delta W$ should increase the measure of banks that screen as it directly increases the premium paid on highly rated assets, which raises the return differential $\Delta R$. This is indeed true if banks with low quality assets choose a pure rating strategy. In other words, for small changes in $\Delta W$, the rating behavior remains unaffected, so there are no additional effects operating. In the case of a mixed rating strategy though, $f_{B}$ will intensify and rating informativeness will decline, in line of our discussion of equation (27). We find that the positive direct effect of $\Delta W$ on screening is exactly offset by an increase in the intensity of rating poor quality assets. Lemma 3 formalizes these results.

\section{Lemma 3 Macroeconomic effects of the change in $\Delta \mathrm{W}$}

In equilibrium, screening effort $\bar{k}^{*}$ and measure of resource allocation $\mu^{*}$ are weakly increasing in $\Delta W$.

Proof. See the appendix.

Thus, our model is consistent with the view that the rise in collateral values in mortgage or business loan markets $(\Delta W \downarrow)$ may have also worked to weaken the screening incentives of the loan originators, thereby aiding rising asset complexity (studied above) in worsening the average quality of loans.

To complete our comparative analysis, it remains to consider the quality of the pool of borrowers $\left(\mu_{0}\right)$ and the cost of rating $c$. Perhaps the most surprising result in this section is that an improvement in the pool of potential borrowers, $\mu_{0}$, may actually worsen the degree of resource misallocation in the economy, i.e. it may imply a lower $\mu^{*}$. This is formalized in Lemma 4 . An increase in $\mu_{0}$ clearly has a direct positive effect on $\mu^{*}$. Ceteris paribus, it can only increase the proportion of good borrowers in the economy. However, an increase in $\mu_{0}$ also unambiguously weakens the incentive to screen (lowers $\bar{k}^{*}$ ) as it implies a better ex-ante distribution of borrowers and makes the option of choosing the loan basket at random more attractive. Condition (28) compares the size of these two effects. The positive effect amounts to $1-F(\bar{k})$, as it operates only through measure $1-F(\bar{k})$ of banks that select their borrowers at random. The negative effect equals $\left(1-\mu_{0}\right) F_{k}(\bar{k}) \Delta R$. It is given by the measure of banks that stop screening $\left(F_{k}(\bar{k}) \Delta R\right)$ multiplied by the loss in the probability of issuing a high quality asset associated with the decision to pick at random $\left(1-\mu_{0}\right)$.

Lemma 4 Macroeconomic effects of the change in the pool of borrowers $\left(\mu_{0}\right)$

The following effects on screening effort $\bar{k}^{*}$ and measure of resource allocation $\mu^{*}$ hold in equilibrium:

a) $\bar{k}^{*}$ is strictly decreasing in $\mu_{0}$. 
b) $\mu^{*}$ is weakly increasing in $\mu_{0}$ if and only if

$$
1-F\left(\bar{k}\left(\mu^{*}\right)\right) \geq\left(1-\mu_{0}\right) F_{k}\left(\bar{k}\left(\mu^{*}\right)\right) \Delta R .
$$

Proof. See the appendix.

Lemma 5 formalizes the effects of the rating cost. Because high quality assets are rated with certainty, an increase in the rating cost $c$ will raise the expected rating cost of a high quality loan basket compared to that of a poor quality loan basket as long as $f_{B}<1$. This direct effect discourages screening, and this is the only effect operating if $f_{B}=0$. Of course, the incentives to screen are unaffected if $f_{B}=1$, because the rating costs increase proportionately for both asset types. If $f_{B}\left(\mu^{*}\right) \in(0,1)$, which is the empirically relevant case, then there is an additional effect of an increase in $c$ that dominates. A greater $c$ reduces the incentive to rate poor quality assets, thereby raising the signaling value of high ratings. This raises the premium paid on highly rated assets, thereby strengthening the incentive to screen.

\section{Lemma 5 Macroeconomic effects of the change in the rating cost (c)}

The following effects on screening effort $\bar{k}^{*}$ and measure of resource allocation $\mu^{*}$ hold in equilibrium:

a) If $f_{B}\left(\mu^{*}\right)=0$, then $\bar{k}^{*}$ and $\mu^{*}$ are strictly decreasing in $c$.

b) If $f_{B}\left(\mu^{*}\right) \in(0,1)$ (the empirically relevant case), then $\bar{k}^{*}$ and $\mu^{*}$ are strictly increasing with $c$.

c) If $f_{B}\left(\mu^{*}\right)=1$, then $\bar{k}^{*}$ and $\mu^{*}$ are independent of $c$.

Proof. See the appendix.

This analysis shows that, just like an increase in $r$, an increase in $c$ can help get the screening effort closer to the efficient level. The intuition is similar. An increase in the rating cost discourages rating activity on the part of poor quality asset issuers. High ratings become more meaningful, and investors are willing to pay more for them. In turn, the high premium paid on highly rated assets incentivizes more banks to engage in screening. The general message here is that there is a benefit to discouraging frivolous rating activity. In contrast, the issuer-pay model applied in practice typically requires pay for published ratings only. Our findings warn against this feature.

\section{Policy Experiments}

Our comparative statics analysis of the previous section showed that the model mechanism is consistent with lots of empirical facts. We have also seen that the strategic rating component and its interaction with the endogenous screening choice play a critical role in generating the model results. In this section, we will show that it is also critical for policy evaluation. We analyze mandatory rating and mandatory ratings disclosure (but voluntary rating) as two policies that may potentially align the decentralized equilibrium allocation with the efficient one. We find that, contrary to conventional wisdom, both policies worsen the degree of resource misallocation.

\subsection{Mandatory Rating}

Consider a policy that dictates that all assets must be rated. At first glance, this policy may appear appealing because the rating technology is indeed informative $(r>0.5)$ and its employment will produce more information in the asset market. We show that this policy is at best ineffective. It makes no difference in the case where all 
assets are already rated in the equilibrium. In all other cases, the policy unambiguously worsens the degree of resource misallocation.

Under mandatory rating, the possibility of hiding the obtained ratings is irrelevant. Because it is perfectly known that everyone is required to obtain a rating, a lack of a rating will signal a hidden poor rating. Therefore, an introduction of the mandatory rating policy into our model is equivalent to setting $f_{B}=f_{G}=1$.

We show that by intensifying the rating activity on the part of sellers of low quality assets, this policy introduces more confusion in the asset market, reducing informativeness of a good rating and therefore dampening the premium paid on highly rated assets. We emphasize that the key intuition is in the fact that the premium paid on highly rated assets $\left(P_{G R}-P_{B R}\right)$ declines in $f_{B}$. In turn, the premium paid on assets with good ratings is what disciplines screening effort at the stage of loan origination. As this premium declines a result of policy intervention - banks are discouraged from expending their resources on screening, and the degree of resource misallocation worsens.

Denoting the measure of good assets in the economy under mandatory rating by $\mu^{m r}$, we formalize our main findings in the proposition below.

\section{Proposition 3 Macroeconomic Implications of Mandatory Rating Policy}

Under the mandatory rating policy, the resource misallocation worsens:

$$
\mu_{m r}^{*} \leq \mu^{*}
$$

The following comparative statics results hold:

$$
\frac{\partial \mu_{m r}^{*}}{\partial r}>0, \quad \frac{\partial \mu_{m r}^{*}}{\partial c}=0, \quad \frac{\partial \mu_{m r}^{*}}{\partial \Delta W}>0
$$

Finally, $\frac{\partial \mu_{m r}^{*}}{\partial \mu_{0}}>0$ if and only if inequality (28) holds.

Proof. To show the first result, it suffices to show that $H(\mu)$, defined in (22), is lower under the mandatory rating policy. This would imply that the fixed point of $\mu=F(\bar{k}(\mu))+(1-F(\bar{k}(\mu))) \mu_{0}$ is lower under this policy.

Recognizing that $H(\mu)$ increases in $\bar{k}(\mu)$ and therefore in $\Delta R$, it suffices to show that

$$
\Delta R_{m r}(\mu) \leq \Delta R(\mu)
$$

for admissible $\mu$. This result follows immediately from the definition of

$$
\begin{aligned}
\Delta R & =\left(r-(1-r) f_{B}\right)\left(P_{G R}-P_{B R}\right)-c\left(1-f_{B}\right) \\
& =\left(r-(1-r) f_{B}\right)\left(\frac{\mu r}{\mu r+(1-\mu) f_{B}(1-r)}-\frac{\mu(1-r)}{\mu(1-r)+(1-\mu)\left(1-f_{B}(1-r)\right)}\right)-c\left(1-f_{B}\right)
\end{aligned}
$$

after employing the expression of $f_{B}(\mu)$ given in Corollary 1. Condition (29) is satisfied with strict inequality in the range of $\mu$ where $f_{B}(\mu)<1$ in the benchmark model. The desired results follow from Lemmas 3-5 after substituting for $f_{B}=1$.

This policy experiment highlights the importance of distinct rating activity of high quality and low quality assets. The fact that poor quality asset issuers know they have a lemon and are allowed to freely act on that knowledge translates into less frequent ratings use on their part. This is important because it helps raise ratings informativeness, and therefore, discipline the screening activity. Our results suggest that effective policy design should take this important channel into account. In light of our analysis, policy design aimed at raising $r$ (i.e. reducing asset complexity or disciplining the behavior of rating agencies) or raising $c$ would be much more 
effective at aligning the equilibrium outcome with the efficient one. It is not surprising that, with mandatory ratings, raising $c$ no longer helps increase screening activity. This is because it can work only by discouraging ratings of low quality assets.

\subsection{Mandatory Ratings Disclosure}

We now consider a policy that dictates that all ratings must be disclosed, although leaves the banks free to make their rating choices. This policy also appears potentially useful as it simply suggests to disclose the information that has already been obtained. However, we find that, for a broad range of parameter values, this policy intensifies the rating activity of bad assets, weakens the incentive to screen and exacerbates the resource misallocation problem in the economy.

With the introduction of mandatory ratings disclosure, investors can differentiate between assets with good ratings, assets with bad ratings, and unrated assets, all of which will trade at potentially distinct prices that we denote by $P_{G R}, P_{B R}$, and $P_{N R}$, respectively. Therefore, we must adjust several definitions in the model economy and review the rating strategies.

A bank with a high quality asset chooses to employ the rating technology $\left(f_{G}=1\right)$ if and only if

$$
r P_{G R}+(1-r) P_{B R}-c>P_{N R}
$$

As in the benchmark model, we consider only the range of parameter values implying that $f_{G}=1$.

Similarly, a bank with a poor quality asset employs the rating technology $\left(f_{B}=1\right)$ if and only if

$$
(1-r) P_{G R}+r P_{B R}-c>P_{N R}
$$

it is indifferent towards rating if the above expression holds with equality and prefers to opt out of rating otherwise.

The expected returns from having issued assets of type $\theta \in\{B, G\}$ are then given by

$$
\begin{aligned}
& R_{G}=r P_{G R}+(1-r) P_{B R}-c-1, \\
& R_{B}=f_{B}\left[(1-r) P_{G R}+r P_{B R}-c\right]+\left(1-f_{B}\right) P_{N R}-1 .
\end{aligned}
$$

Our assumption of competitive markets implies that investors make zero profits, i.e. that equilibrium prices on assets with good ratings, bad ratings and no ratings reflect their expected returns, as perceived by investors:

$$
\begin{aligned}
& P_{G R}=W_{G} \operatorname{Pr}_{G \mid G R}+W_{B}\left[1-\operatorname{Pr}_{G \mid G R}\right]=\Delta W \operatorname{Pr}_{G \mid G R}+W_{B} \\
& P_{B R}=W_{G} \operatorname{Pr}_{G \mid B R}+W_{B}\left[1-\operatorname{Pr}_{G \mid B R}\right]=\Delta W \operatorname{Pr}_{G \mid B R}+W_{B} \\
& P_{N R}=W_{G} \operatorname{Pr}_{G \mid N R}+W_{B}\left[1-\operatorname{Pr}_{G \mid N R}\right]=\Delta W \operatorname{Pr}_{G \mid N R}+W_{B}
\end{aligned}
$$

Finally, we require that investors' beliefs are consistent with the equilibrium outcomes:

$$
\begin{aligned}
\operatorname{Pr}_{G \mid G R} & =\frac{\mu r}{\mu r+(1-\mu) f_{B}(1-r)}, \\
\operatorname{Pr}_{G \mid B R} & =\frac{\mu(1-r)}{\mu(1-r)+(1-\mu) f_{B} r}, \\
\operatorname{Pr}_{G \mid N R} & =0 .
\end{aligned}
$$


The last belief is zero because high quality assets are always rated $\left(f_{G}=1\right)$ and disclosed.

Other than the fact that three types of assets are now traded in asset markets, the equilibrium in the economy under the mandatory ratings disclosure policy is defined as in the benchmark model. It is given by the marginal screener $\bar{k}^{*}$, the rating strategies $f_{G}^{*}=1$ and $f_{B}^{*}$, the measure of good borrowers in the economy $\mu^{*}$, investors' beliefs regarding asset quality conditional on the observed rating $\left\{\operatorname{Pr}_{G \mid G R}^{*}, \operatorname{Pr}_{G \mid B R}^{*}, \operatorname{Pr}_{G \mid N R}^{*}\right\}$ and asset prices $\left\{P_{G R}^{*}, P_{B R}^{*}, P_{N R}^{*}\right\}$ such that:

1. Given the asset prices, banks of type $k \leq \bar{k}^{*}$ find it optimal to screen their borrowers, i.e. the screening condition (5) is satisfied when we substitute for $R_{G}$ and $R_{B}$ defined in (33) and (32), while the opposite is true for banks of type $k>\bar{k}^{*}$.

2. Given the asset prices, banks that issued type $\theta$ assets find it optimal to rate according to $f_{\theta}^{*}$ (i.e. the rating optimality conditions (30) and (31) are satisfied).

3. Given investors' beliefs, asset prices reflect expected returns: conditions (34) - (36) hold.

4. Investors' beliefs $\left\{\operatorname{Pr}_{G \mid G R}^{*}, \operatorname{Pr}_{G \mid N R}^{*}\right\}$ are consistent with the equilibrium outcomes: (37) - (39) hold.

5. The measure of resource allocation in the economy $\mu^{*} \in(0,1)$ is determined by the optimal screening strategies, summarized by $\bar{k}^{*}$ :

$$
\mu^{*}=F\left(\bar{k}^{*}\right)+\left(1-F\left(\bar{k}^{*}\right)\right) \mu_{0} .
$$

First of all, we find that under mandatory disclosure, it is never the case that $f_{B}=0$. The intuition is as follows. If $f_{B}=0$ and $f_{G}>0$, then the disclosure of any rating, whether it is good or bad, would signal with certainty that the asset is of high quality. The equilibrium asset prices generated by such beliefs would incentivize poor asset issuers to rate their assets, which contradicts the assumption of $f_{B}=0$. Lemma ?? characterizes the rating strategy $f_{B}$ for a given measure of resource allocation $\mu$.

Lemma 6 Mandatory Ratings Disclosure: Rating Strategy $f_{B}$ (for a fixed $\mu$ ). For a given measure of resource allocation $\mu \in(0,1]$, we have $f_{G}=1$ and $f_{B}$ is summarized as

$$
f_{B}=\left\{\begin{aligned}
1 & \tilde{c}<\frac{\mu r(1-r)}{[\mu r+(1-\mu)(1-r)][\mu(1-r)+(1-\mu) r]} \\
f_{B}^{m i x} \in(0,1) & \text { if } \frac{\mu r(1-r)}{[\mu r+(1-\mu)(1-r)][\mu(1-r)+(1-\mu) r]} \leq \quad \tilde{c}<1,
\end{aligned}\right.
$$

where the mixed strategy is given by $f_{B}^{\operatorname{mix}}=\mu \frac{(1+2 \tilde{c})\left(r-r^{2}\right)-\tilde{c}+\sqrt{10 \tilde{c} r^{2}-(16 \tilde{c}+2) r^{3}+(8 \tilde{c}+1) r^{4}+4 \tilde{c}^{2}\left(r^{2}-r\right)+(\tilde{c}-r)^{2}}}{2 \tilde{c} r(1-\mu)(1-r)} .^{20}$

Proof. See the appendix.

The main result is formalized in the proposition below. We show that the mandatory ratings disclosure policy tends to weaken the incentive to screen. The intuition for this result is as follows. The introduction of this policy no longer allows to pass off missing ratings as undisclosed false ratings. Even poor ratings now serve as a positive signal. This encourages the rating behavior on the part of poor asset issuers. In fact, it is seen immediately that $f_{B}^{m i x}(\mu)$ is strictly greater than its counterpart in the benchmark model (defined in Corollary 1) for all $\mu$. As a result, markets are confused and rating informativeness is reduced, just like in the case of the mandatory rating policy. As the informational value of good ratings declines, so does the expected return to screening, which compounds the resource misallocation in the economy.

${ }^{20}$ This expression is a solution to $(1-r) P_{G R}+r P_{B R}-c=P_{N R}$. 
Proposition 4 Macroeconomic Implications of Mandatory Ratings Disclosure

If $\mu^{*} \in\left(0, \frac{1-r-\tilde{c}}{1-r-r \tilde{c}}\right),{ }^{21}$ the resource misallocation worsens under the mandatory ratings disclosure policy:

$$
\mu_{m d}^{*} \leq \mu^{*}
$$

Proof. See the appendix.

Recall from Corollary 1 that $f_{B}(\mu)>0$ in the range of $\mu \in\left(0, \frac{1-r-\tilde{c}}{1-r-r \tilde{c}}\right)$. Therefore the result applies in the empirically relevant cases. Figure 4 illustrates the comparison between the benchmark economy and the mandatory ratings disclosure economy for the following parameterization: $r=0.8, c=0.1, W_{G}=1.1$, $W_{B}=0.3$. Panel b shows the rating intensity. Because this is the case where $c>(1-r)(2 r-1) \Delta W$, the benchmark rating function $f_{B}(\mu)$ is below 1 on the entire range of $\mu \in\left(0, \frac{1-r-\tilde{c}}{1-r-r \tilde{c}}\right)$. Consistent with our discussion, $f_{B}^{m d}(\mu)>f_{B}(\mu)$ for all $\mu$. This results in the lower premium paid on high quality assets under mandatory ratings disclosure (panel d) and lower returns to screening $\Delta R(\mu)$ (panel c). Note that to show that $\mu_{m d}^{*} \leq \mu^{*}$, it suffices to show that $\Delta R(\mu)>\Delta R^{m d}(\mu)$ in the range of admissible $\mu$. This is because $\bar{k}(\mu)=\left(1-\mu_{0}\right) \Delta R(\mu)$ and $H(\mu)$ increases in $\bar{k}(\mu)$. Panel a illustrates the actual equilibrium level of good projects in both economies as the intersection of the 45 degree line with the benchmark $H(\mu)$ and $H_{m d}(\mu)$, derived under the assumption that $\mu_{0}=0.6$ and a linear cumulative distribution function of banks, $F(k)=k$.

\section{Conclusion}

We developed a general equilibrium model that allowed us to study the interaction of information production in secondary markets for loans, via ratings and their disclosure, and screening intensity at the stage of loan origination. The model is consistent with several puzzling features appearing in pre-crisis data, such as the decline in screening effort, intensified rating activity, ratings inflation, the decline in the premium paid on highly rated assets, and rising prevalence of triple-A ratings. The model provides insight into what determines screening effort at the stage of loan origination and explains why it is less than optimal. The premium paid on highly rated assets emerges as the main determinant of screening effort. Because the rating technology is imperfect, this premium is insufficient to induce the efficient level of screening. However, the fact that banks know their asset quality and produce ratings according to their information helps keep the premium high. Mandatory rating and mandatory ratings disclosure policies interfere with this decision margin, thereby reducing informativeness of high ratings, lowering the premium paid on them, and exacerbating the credit misallocation problem. Our findings caution against these regulatory policies and suggest that policy design aimed at raising rating accuracy (e.g. policies that regulate asset complexity) and/or raising the cost of ratings would be more effective at aligning equilibrium outcomes with the efficient one.

${ }^{21}$ This condition is more stringent than needed. 


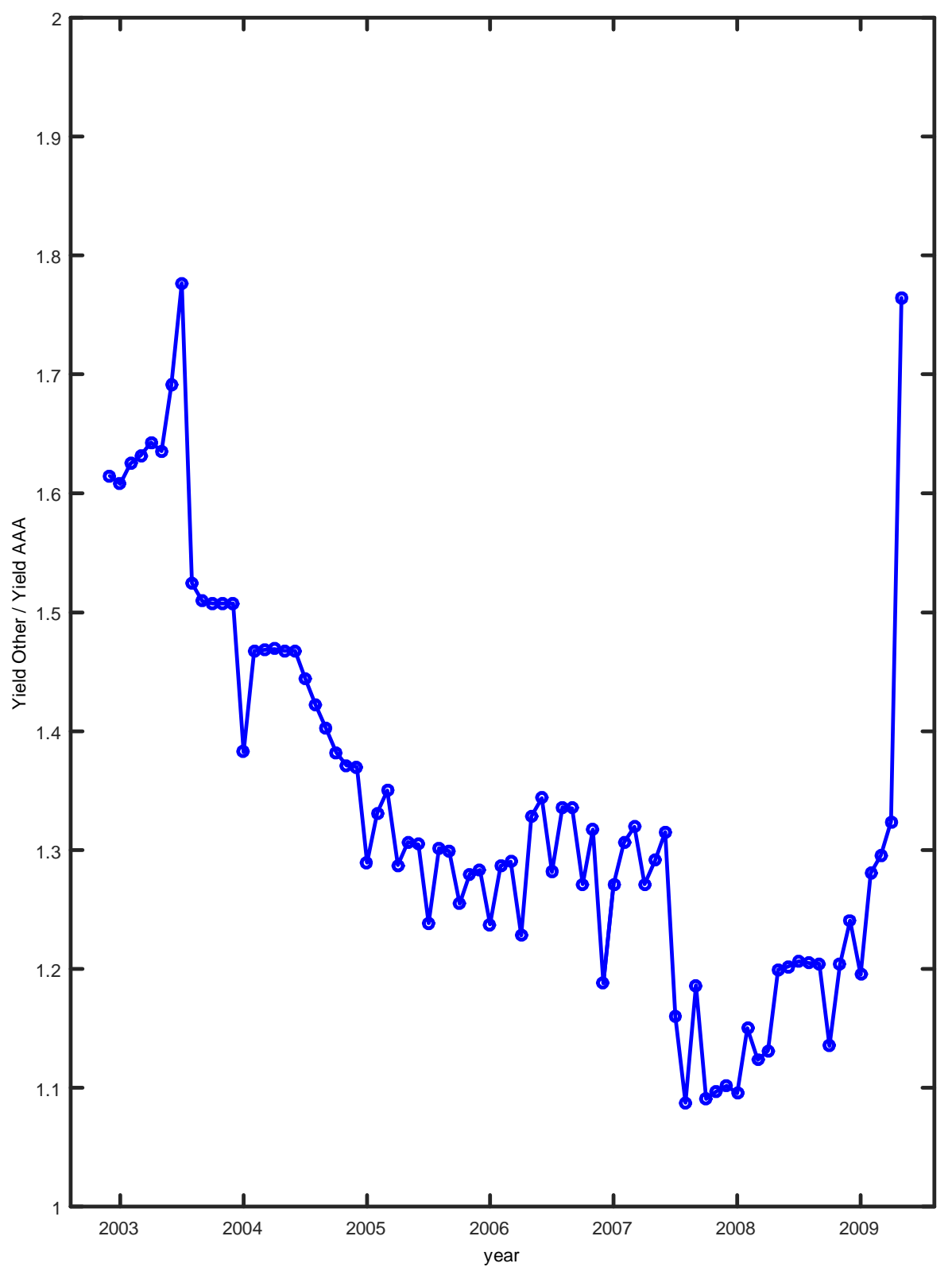

Figure 1. Difference in Yields of AAA-rated and Other Tranches

Notes. Source: ABSnet (restricted) deal data. The following restrictions were applied to the dataset. Region: United States; Deal Type: Asset Backed Security; Asset Class: Small Business Loans. Yield AAA is computed as the average yield on tranches with at least one triple-A rating. Yield Other is computed as the average yield on all other tranches. 


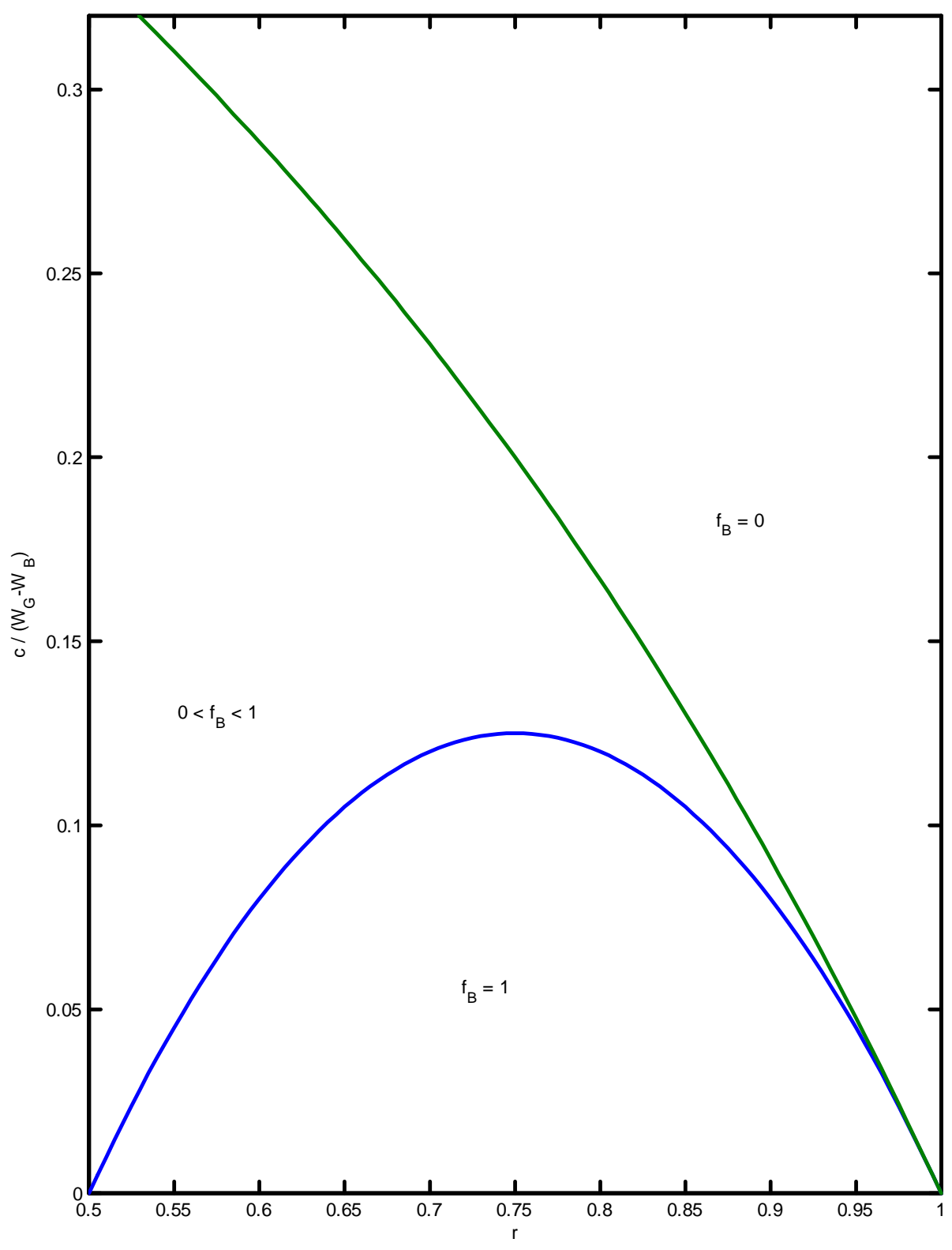

Figure 2. Equilibrium Rating Strategy

Notes: This figure helps visualize Lemma 1. For a given resource allocation $\mu^{*}$, this figure reports the optimal rating strategy by holders of type $B$ assets in the space of two exogenous quantities: the rating accuracy $r$ and the rating cost $c$ normalized by the repayment differential $W_{G}-W_{B}$. 

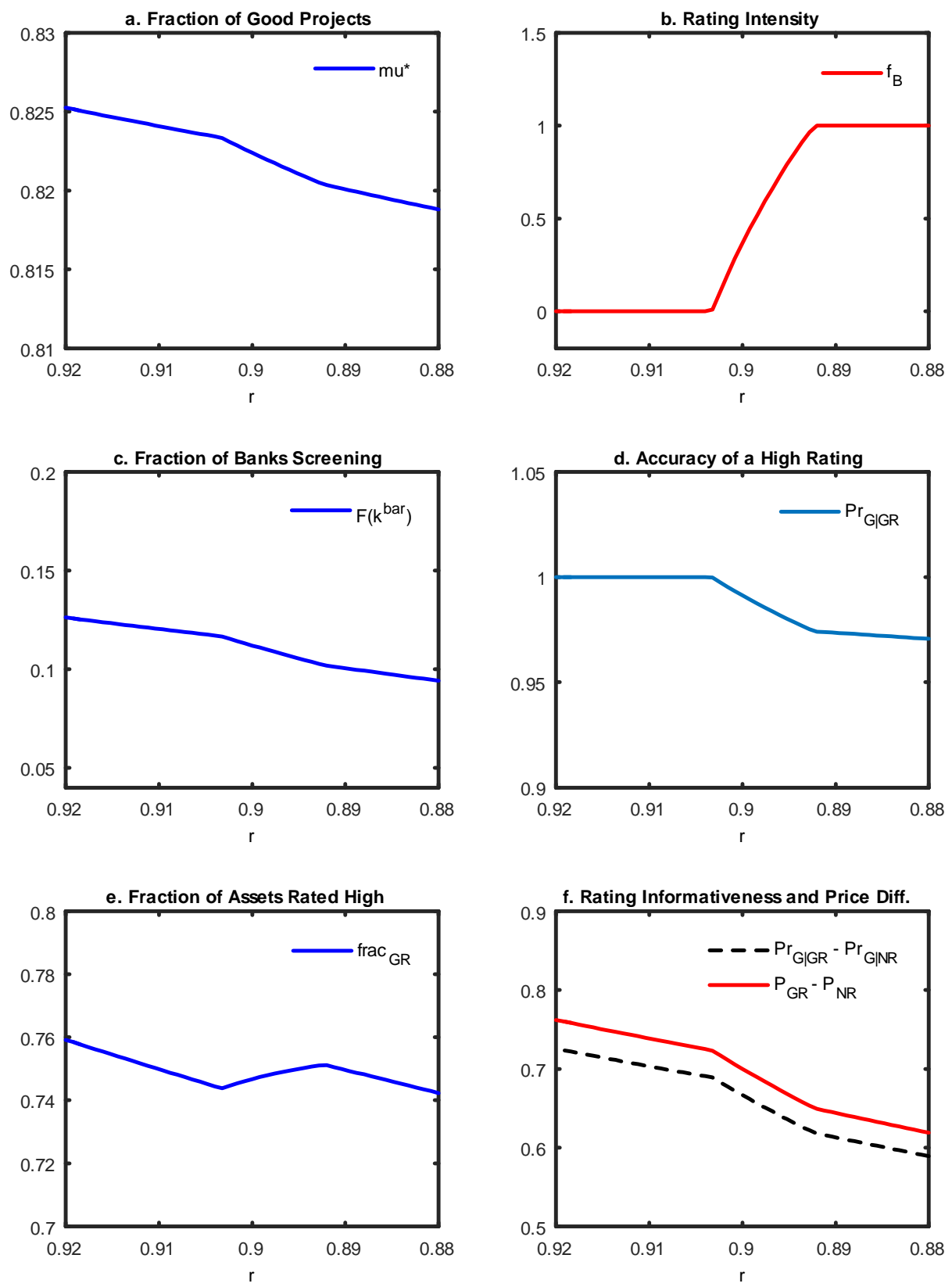

Figure 3. Equilibrium Effects of Decreasing the Rating Precision

Notes: This figure illustrates the possible equilibrium effects of decreasing the rating accuracy parameter $r$. 

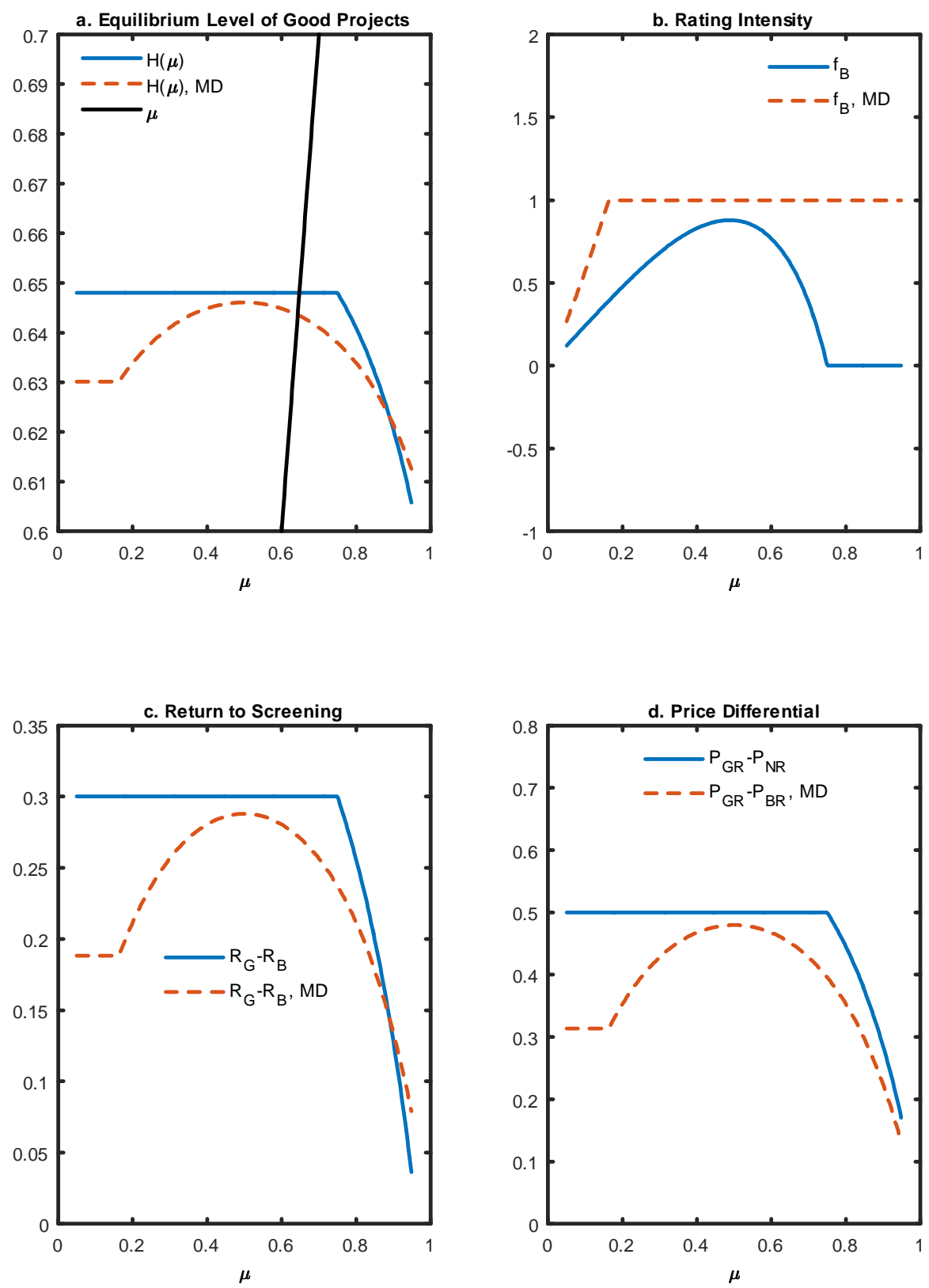

Figure 4. Benchmark Economy vs. Economy under Mandatory Ratings Disclosure Policy

Notes: This figure visualizes Proposition 4. For each of the economies, this figure reports the rating intensity function, premium paid on high quality assets and returns to screening. Panel a shows the determination of the equilibrium level of good projects in the economy as an intersection of the 45 degree line and function $H(\mu)$. 


\section{A. Proof of Lemma 1}

\section{Rating strategy $f_{B}$.}

Case 1. $f_{B}=1$. From (1), this strategy is optimal whenever $(1-r)\left(P_{G R}-P_{N R}\right)>c$. Substituting for prices from the zero profit conditions (8) and (9), we have

$$
(1-r) \Delta W \Delta \operatorname{Pr}>c,
$$

where $\Delta \operatorname{Pr} \equiv \operatorname{Pr}_{G \mid G R}-\operatorname{Pr}_{G \mid N R}$. Substituting for beliefs from the consistency conditions (8) and (9) and from $f_{B}=1$ gives the necessary and sufficient condition for the above inequality:

$$
\begin{aligned}
(1-r) \Delta W & {\left[\frac{\mu r}{\mu r+(1-\mu)(1-r)}-\frac{\mu(1-r)}{\mu(1-r)+r(1-\mu)}\right]>c, \text { or } } \\
(1-r) \frac{\mu(1-\mu)(2 r-1)}{(r-\mu(2 r-1))(\mu(2 r-1)+(1-r))} & >\frac{c}{\Delta W} .
\end{aligned}
$$

Case 2. $f_{B}=0$. Following the same steps as in Case 1, we find this strategy is optimal whenever

$$
(1-r) \Delta W \Delta \operatorname{Pr}<c .
$$

Substituting for beliefs from the consistency conditions and for $f_{B}=0$, we obtain

$$
\begin{aligned}
(1-r) \Delta W\left[1-\frac{\mu(1-r)}{\mu(1-r)+(1-\mu)}\right] & <c, \text { or } \\
(1-r)\left[\frac{1-\mu}{1-r \mu}\right] & <\frac{c}{\Delta W} .
\end{aligned}
$$

Case 3. $f_{B} \in(0,1)$. The mixed strategy is optimal whenever

$$
(1-r) \Delta W \Delta \operatorname{Pr}=c .
$$

Substituting into the above equality for beliefs from (8) and (9) gives

$$
(1-r)\left[\frac{\mu r}{\mu r+(1-\mu) f_{B}(1-r)}-\frac{\mu(1-r)}{\mu(1-r)+(1-\mu)\left[\left(1-f_{B}\right)+f_{B} r\right]}\right]=\frac{c}{\Delta W} .
$$

It is straightforward to show that the positive solution to this equation is given by

$$
f_{B}^{m i x}=\frac{\tilde{c}(1-2 \mu r)+\mu(1-r)-\sqrt{(\tilde{c}+\mu)^{2}-\mu^{2} r(2-r)-(6-4 r) \tilde{c} r \mu}}{2 \tilde{c}(1-r)(1-\mu)} .
$$

The optimal strategy $f_{B}$ is given by $f_{B}^{m i x}$ derived above, but bounded by 0 from below and 1 from above. Thus we have $f_{B} \in(0,1)$ whenever

$$
(1-r) \frac{\mu(1-\mu)(2 r-1)}{(r-\mu(2 r-1))(\mu(2 r-1)+(1-r))}<\frac{c}{\Delta W}<(1-r)\left[\frac{1-\mu}{1-r \mu}\right] .
$$

The first inequality appearing in the expression above is derived by setting $f_{B}^{m i x}<1$, and the second inequality is derived by setting $f_{B}^{m i x}>0$.

Rating strategy $f_{G}$.

To ensure that $f_{G}=1$, we must impose that

$$
r \Delta W \Delta \operatorname{Pr}>c .
$$

This inequality holds whenever $f_{B}>0$, because in that case $r \Delta W \Delta \operatorname{Pr}>(1-r) \Delta W \Delta \operatorname{Pr} \geq c$. 
However, on the space of parameters that implies $f_{B}=0$, we need an additional restriction. Substituting for $\Delta \operatorname{Pr}$ in the case of $f_{B}=0$ and simplifying, we obtain

$$
r \Delta W \Delta \operatorname{Pr}=r \Delta W\left[\frac{1-\mu}{1-r \mu}\right]>c .
$$

The result follows.

\section{B. Proof of Proposition 1}

Because $H(\cdot)$ is continuous, there exists at least one fixed point of $H(\cdot)$ whenever $H(0)>0$ and $H(\bar{\mu})<\bar{\mu}$. The fixed point is unique if $H^{\prime}(\mu)<1$ on the entire range of $\mu \in(0, \bar{\mu})$. The constants $\mu_{1}, \mu_{2}, \mu_{3}$ and $\bar{\mu}$ used in the proof are defined in the statement of Corollary 1.

\section{Existence}

Recall the definition of $H:[0, \bar{\mu}] \rightarrow\left[\mu_{0}, 1\right]$ given in $(22):$

$$
H(\mu)=F(\bar{k}(\mu))+\left[1-F(\bar{k}(\mu)] \mu_{0} .\right.
$$

We substitute for the marginal screener

$$
\bar{k}(\mu)=\left(1-\mu_{0}\right)\left[\Delta W \Delta \operatorname{Pr}(\mu)\left[r-(1-r) f_{B}(\mu)\right]-\left(1-f_{B}(\mu)\right) c\right]
$$

using (??) and for rating informativeness

$$
\Delta \operatorname{Pr}(\mu)=\frac{\mu r}{\mu r+(1-\mu) f_{B}(\mu)(1-r)}-\frac{\mu(1-r)}{\mu(1-r)+(1-\mu)\left[\left(1-f_{B}(\mu)\right)+f_{B}(\mu) r\right]}
$$

using (8) and (9).

We use the resulting expression to find $H(0)$. We know from Lemma 1 that $f_{B}(0)=0$ and $f_{G}(0)=1$. Hence, $\Delta \operatorname{Pr}(0)=1$ and $\bar{k}(0)=\left(1-\mu_{0}\right)[\Delta W r-c]>0$. It follows that

$$
H(0)=F\left(\left(1-\mu_{0}\right)[\Delta W r-c]\right)+\left[1-F\left(\left(1-\mu_{0}\right)[\Delta W r-c]\right)\right] \mu_{0}>F(0)+[1-F(0)] \mu_{0}>0 .
$$

Our next objective is to find $H(\bar{\mu})$. By Lemma $1, f_{B}(\bar{\mu})=0$ and $f_{G}(\bar{\mu})=1$. Hence, $\Delta \operatorname{Pr}(\bar{\mu})=\frac{1-\bar{\mu}}{1-r \bar{\mu}}$ and

$$
\begin{aligned}
\bar{k}(\bar{\mu}) & =\left(1-\mu_{0}\right)\left[\Delta W \Delta \operatorname{Pr}(\bar{\mu})\left[r-(1-r) f_{B}(\bar{\mu})\right]-\left(1-f_{B}(\bar{\mu})\right) c\right]= \\
& =\left(1-\mu_{0}\right)\left[\Delta W r \frac{1-\bar{\mu}}{1-r \bar{\mu}}-c\right] \\
& =\left(1-\mu_{0}\right)\left[\Delta W r \frac{1-\frac{r-\tilde{c}}{r(1-\tilde{c})}}{1-\frac{r-\tilde{c}}{1-\tilde{c}}}-c\right] \\
& =\left(1-\mu_{0}\right)\left[\Delta W r \frac{\tilde{c}}{r}-c\right]=\left(1-\mu_{0}\right)[c-c]=0 .
\end{aligned}
$$

Hence,

$$
H(\bar{\mu})=F(0)+[1-F(0)] \mu_{0}=\mu_{0} .
$$

The assumption $\mu_{0}<\bar{\mu}$ then implies that $H(\bar{\mu})<\bar{\mu}$. We showed that $H(0)>0$ and $H(\bar{\mu})<\bar{\mu}$, which implies that equation $\mu=H(\mu)$ has at least one solution.

\section{Uniqueness}

Now we move on to discuss uniqueness. Differentiating $H(\mu)$, we obtain

$$
H^{\prime}(\mu)=\left(1-\mu_{0}\right) F_{\bar{k}} \frac{\partial \bar{k}}{\partial \mu} \text {. }
$$


Range 1. First, consider the highest admissible range of $\mu \in\left(\mu_{3}, \bar{\mu}\right)$, where $f_{B}=0$ by Lemma 1 . Substituting for $f_{B}$ into (18) and differentiating, we obtain $\frac{\partial \bar{k}}{\partial \mu}=\frac{-\left(1-\mu_{0}\right) r(1-r) \Delta W}{(1-r \mu)^{2}}$ and therefore

$$
H^{\prime}(\mu)=-F_{\bar{k}}\left(1-\mu_{0}\right)^{2}\left(\frac{r(1-r) \Delta W}{(1-r \mu)^{2}}\right) \leq 0
$$

Range 2. If parameters satisfy $\tilde{c} \leq(1-r)(2 r-1)$, consider $\mu \in\left(0, \mu_{1}\right)$ and $\mu \in\left(\mu_{2}, \mu_{3}\right)$. If instead parameters satisfy $\tilde{c}>(1-r)(2 r-1)$, consider the entire range of $\mu \in\left(0, \mu_{3}\right)$. By Lemma 1 , we have $f_{B} \in(0,1)$ for these values of $\mu$, and therefore $\Delta \operatorname{Pr}=\frac{c}{(1-r) \Delta W}$. Substituting this into (18) and differentiating gives us $\frac{\partial \bar{k}}{\partial \mu}=0$ and therefore

$$
H^{\prime}(\mu)=0 \text {. }
$$

Range 3. It remains to consider the range $\mu \in\left(\mu_{1}, \mu_{2}\right)$, relevant only if parameters satisfy $\tilde{c} \leq(1-r)(2 r-1)$. By Lemma $1, f_{B}=1$. Substituting that into (18) and differentiating, we obtain

$$
\frac{\partial \bar{k}}{\partial \mu}=\left(1-\mu_{0}\right) \Delta W \frac{r(2 r-1)^{2}(2 \mu-1)(r-1)}{(r-\mu(2 r-1))^{2}(\mu(2 r-1)+(1-r))^{2}},
$$

which then implies

$$
\begin{aligned}
H^{\prime}(\mu) & =F_{\bar{k}}\left(1-\mu_{0}\right)^{2} \Delta W \frac{(2 r-1)^{2}(1-2 \mu) r(1-r)}{(r-\mu(2 r-1))^{2}(\mu(2 r-1)+(1-r))^{2}}= \\
& =F_{\bar{k}}\left(1-\mu_{0}\right)^{2} \Delta W \frac{(2 r-1)^{2}(1-2 \mu)}{r(1-r)\left(1+\mu(1-\mu)\left(\frac{r^{2}+(1-r)^{2}}{r(1-r)}-2\right)\right)^{2}} .
\end{aligned}
$$

The resulting derivative is a decreasing function of $\mu$, with a zero at $\mu=0.5$.

If $\mu \geq 0.5$, then $H^{\prime}(\mu) \leq 0$. If $\mu<0.5$, then $H^{\prime}(\mu)>0$, and it is maximized out at $\mu_{1}$. Therefore, we can bound $H^{\prime}(\mu)$ on the range of $\mu \in\left(\mu_{1}, 0.5\right)$ by setting $H^{\prime}\left(\mu_{1}\right)<1$.

Substituting the expression for $\mu_{1}$ given in (17) into the expression for $H^{\prime}(\mu)$ given in (44) and noting that $\mu_{1}\left(1-\mu_{1}\right)$ simplifies to $\frac{\tilde{c} r(1-r)}{(2 r-1)(1-r-\tilde{c}(2 r-1))}$, we obtain

$$
\begin{aligned}
H^{\prime}(\mu) & <H^{\prime}\left(\mu_{1}\right)=F_{\bar{k}}\left(1-\mu_{0}\right)^{2} \Delta W \frac{\frac{(2 r-1)^{2}}{r(1-r)} \sqrt{\frac{(1-r)(2 r-1)-\tilde{c}}{(2 r-1)(\tilde{c}+1-2 \tilde{c} r-r)}}}{\left(1+\frac{\tilde{c} r(1-r)}{(2 r-1)(1-r-\tilde{c}(2 r-1))}\left(\frac{r^{2}+(1-r)^{2}}{r(1-r)}-2\right)\right)^{2}}= \\
& =F_{\bar{k}}\left(1-\mu_{0}\right)^{2} \Delta W \frac{(2 r-1)^{2}}{r(1-r)} \sqrt{\frac{(1-r)(2 r-1)-\tilde{c}}{(2 r-1)(1-r-\tilde{c}(2 r-1))^{2}}} /\left(\frac{1-r}{(1-r-\tilde{c}(2 r-1))}\right)^{2} \\
& =\bar{f}\left(1-\mu_{0}\right)^{2} \Delta W \frac{(2 r-1)^{2}}{r(1-r)} \sqrt{\frac{(1-r)-\tilde{c} /(2 r-1)}{(1-r-\tilde{c}(2 r-1))}} /\left(\frac{1-r}{(1-r-\tilde{c}(2 r-1))}\right)^{2}<1,
\end{aligned}
$$

where $\bar{f}=\sup _{k \in[0,1]} F^{\prime}(k)$, and the last inequality is satisfied by the premise.

To summarize, we found that $H(\mu)$ is weakly decreasing in the entire range of $\mu \in(0, \bar{\mu})$ if $\tilde{c}>(1-r)(2 r-1)$. It is also weakly decreasing in the range of $\mu \in(0.5, \bar{\mu})$ if $\tilde{c} \leq(1-r)(2 r-1)$. In all cases, $H^{\prime}(\mu)<1$, which ensures that equation $\mu=H(\mu)$ has exactly one solution.

It follows that the equilibrium exists, and it is unique. 


\section{Proof of Lemma 2}

From the equilibrium condition $\mu^{*}(r)=H\left(\mu^{*}(r), r\right)$, we obtain

$$
\frac{\partial \mu^{*}}{\partial r}=\frac{H_{r}}{1-H_{\mu}}
$$

By Proposition 1, we know that $1-H_{\mu}>0$. Therefore, the sign of $\frac{\partial \mu^{*}}{\partial r}$ is determined by the sign of $H_{r}$.

Recalling the definition of $H$,

$$
H(\mu, r)=F(\bar{k}(\mu, r))+(1-F(\bar{k}(\mu, r))) \mu_{0},
$$

we see that $H(\mu, \cdot)$ is increasing in $r$ if and only if $\bar{k}(\mu, \cdot)$ is increasing in $r$. Recalling the expression for the marginal screener,

$$
\begin{aligned}
\bar{k}(\mu, r) & =\left(1-\mu_{0}\right)\left(R_{G}(\mu, r)-R_{B}(\mu, r)\right) \\
& =\left(1-\mu_{0}\right)\left\{\left(r-(1-r) f_{B}(\mu, r)\right) \Delta W \Delta \operatorname{Pr}(\mu, r)-\left(1-f_{B}\right) c\right\},
\end{aligned}
$$

we see that $r$ enters through two channels. An increase in the rating precision directly increases the payoff to screening by increasing the probability that holders of high quality assets will receive a good rating and sell their assets at a premium and by decreasing the probability that holders of poor quality assets will receive a good rating in error and sell at a premium. There is also an indirect effect working through $f_{B}$ which influences the actual premium paid on a highly rated asset. There are two cases to consider.

Case 1. Suppose that $f_{B} \in(0,1)$. Then $\Delta W \Delta \operatorname{Pr}=\frac{c}{(1-r)}$. This means that rating informativeness and hence the premium paid on high quality assets also increase in $r$. Both effects work in the same direction. Formally, we substitute for $\Delta \operatorname{Pr}$ into (45) to obtain $\bar{k}=\frac{2 r-1}{1-r} c \mu_{0}$, which is clearly increasing in $r$. Hence, $\frac{\partial \bar{k}^{*}}{\partial r}>0$ and $\frac{\partial \mu^{*}}{\partial r}>0$.

Case 2. Suppose that $f_{B} \in\{0,1\}$. Then $f_{B}$ is constant in the neighborhood of $\mu^{*}$, and therefore

$$
\frac{\partial\left(R_{G}-R_{B}\right)}{\partial r}=\left(1+f_{B}\right) \Delta W \Delta \operatorname{Pr}+\left(r-(1-r) f_{B}\right) \Delta W \frac{\partial \Delta \operatorname{Pr}}{\partial r}>0,
$$

which implies that $\frac{\partial \bar{k}^{*}}{\partial r}>0$ and $\frac{\partial \mu^{*}}{\partial r}>0$.

\section{Proof of Lemma 3}

From the equilibrium condition $\mu^{*}(\Delta W)=H\left(\mu^{*}(\Delta W), \Delta W\right)$, we obtain

$$
\frac{\partial \mu^{*}}{\partial \Delta W}=\frac{H_{\Delta W}}{1-H_{\mu}}
$$

By Proposition 1, we know that $1-H_{\mu}>0$. Therefore, the sign of $\frac{\partial \mu^{*}}{\partial \Delta W}$ is determined by the sign of $H_{\Delta W}$.

Recalling the definition of $H$ from (22),

$$
H(\mu, \Delta W)=F(\bar{k}(\mu, \Delta W))+(1-F(\bar{k}(\mu, \Delta W))) \mu_{0},
$$

we see that $H(\mu, \cdot)$ is increasing in $\Delta W$ if and only if $\bar{k}(\mu, \cdot)$ is increasing in $\Delta W$.

Recalling the expression for the marginal screener from (18),

$$
\begin{aligned}
\bar{k}(\mu, \Delta W) & =\left(1-\mu_{0}\right)\left(R_{G}(\mu, \Delta W)-R_{B}(\mu, \Delta W)\right) \\
& =\left(1-\mu_{0}\right)\left\{\left[r-(1-r) f_{B}(\mu, \Delta W)\right] \Delta W \Delta \operatorname{Pr}(\mu, \Delta W)-\left(1-f_{B}(\mu, \Delta W) c\right)\right\},
\end{aligned}
$$

note that $\Delta W$ enters it through two channels.

First, a higher $\Delta W$ implies that the good project repays relatively more, thereby directly raising $R_{G}-R_{B}$ and increasing the incentive to screen. Second, $\Delta W$ affects $\bar{k}$ indirectly by inducing changes in the rating 
intensity $f_{B}$. There are two cases to consider.

Case 1. Suppose that $f_{B}\left(\mu^{*}\right) \in(0,1)$. Then $\Delta W \Delta \operatorname{Pr}=\frac{c}{(1-r)}$, and therefore

$$
\bar{k}(\mu, \Delta W))=\left(1-\mu_{0}\right) c \frac{2 r-1}{1-r},
$$

which is independent of $\Delta W$. It follows that $H_{\Delta W}=0$, and therefore $\frac{\partial \mu^{*}}{\partial \Delta W}=0$.

Case 2. Suppose that $f_{B}\left(\mu^{*}\right) \in\{0,1\}$. Then $f_{B}$ is constant in the neighborhood of $\mu^{*}$, and only the positive direct effect of $\Delta W$ remains. It follows that $\frac{\partial \bar{k}^{*}}{\partial \Delta W}>0$ and $\frac{\partial \mu^{*}}{\partial \Delta W}>0$.

\section{E. Proof of Lemma 4}

From the equilibrium condition $\mu^{*}\left(\mu_{0}\right)=H\left(\mu^{*}\left(\mu_{0}\right), \mu_{0}\right)$, we obtain

$$
\frac{\partial \mu^{*}}{\partial \mu_{0}}=\frac{H_{\mu_{0}}}{1-H_{\mu}}
$$

By Proposition 1, we know that $1-H_{\mu}>0$. Therefore, the sign of $\frac{\partial \mu^{*}}{\partial \mu_{0}}$ is determined by the sign of $H_{\mu_{0}}$.

Recalling the definition of $H$,

$$
H\left(\mu, \mu_{0}\right)=F\left(\bar{k}\left(\mu, \mu_{0}\right)\right)+\left(1-F\left(\bar{k}\left(\mu, \mu_{0}\right)\right)\right) \mu_{0},
$$

we obtain

$$
\begin{aligned}
\frac{\partial H}{\partial \mu_{0}} & =1+\left(1-\mu_{0}\right) F_{k}(\bar{k}) \frac{\partial \bar{k}}{\partial \mu_{0}}-F(\bar{k}) \\
& =(1-F(\bar{k}))+\left(1-\mu_{0}\right) F_{k}(\bar{k}) \frac{\partial \bar{k}}{\partial \mu_{0}} .
\end{aligned}
$$

Employing the expression for the marginal screener, $\bar{k}\left(\mu, \mu_{0}\right)=\left(1-\mu_{0}\right) \Delta R$ and noting that $\Delta R$ is independent of $\mu_{0},{ }^{22}$ we obtain $\frac{\partial \bar{k}}{\partial \mu_{0}}=-\Delta R$.

Using it in the derivative in (46), we obtain

$$
\frac{\partial H}{\partial \mu_{0}}=(1-F(\bar{k}))-\left(1-\mu_{0}\right) F_{k}(\bar{k}) \Delta R
$$

As a consequence, the following holds.

We have $\mu^{*}$ is weakly increasing in $\mu_{0}$ if

$$
\mu_{0} \geq 1-\left[\frac{1-F(\bar{k})}{F_{k}(\bar{k})}\right] \frac{1}{\Delta R},
$$

and $\mu^{*}$ is weakly decreasing in $\mu_{0}$ otherwise.

\footnotetext{
${ }^{22}$ To see this, consider the following cases. Suppose $f_{B} \in(0,1)$, then $(27)$ holds. Using it in the expression for $\Delta R$ reveals that the effect of $f_{B}$ cancels out, and hence $\Delta R$ is independent of $\mu_{0}$ :

$$
\begin{aligned}
\Delta R & =\left[r-(1-r) f_{B}\right] \Delta W \Delta \operatorname{Pr}-\left(1-f_{B}\right) c \\
& =\frac{(2 r-1) c}{1-r} .
\end{aligned}
$$

Alternatively, $f_{B}$ is either 0 or 1 . In this case, the effect of $\mu_{0}$ through $f_{B}$ is not present because $f_{B}$ is constant. Noting that $\Delta \operatorname{Pr}$ is independent of $\mu_{0}$, we see that $\Delta R$ is independent of $\mu_{0}$.
} 


\section{F. Proof of Lemma 5}

From the equilibrium condition $\mu^{*}(c)=H\left(\mu^{*}(c), c\right)$, we obtain

$$
\frac{\partial \mu^{*}}{\partial c}=\frac{H_{c}}{1-H_{\mu}}
$$

By Proposition 1, we know that $1-H_{\mu}>0$. Therefore, the sign of $\frac{\partial \mu^{*}}{\partial c}$ is determined by the sign of $H_{c}$.

Recalling the definition of $H$,

$$
H(\mu, c)=F(\bar{k}(\mu, c))+(1-F(\bar{k}(\mu, c))) \mu_{0},
$$

we see that $H(\mu, \cdot)$ is increasing in $c$ if and only if $\bar{k}(\mu, \cdot)$ is increasing in $c$.

Recalling the expression for the marginal screener,

$$
\begin{aligned}
\bar{k}(\mu, c) & =\left(1-\mu_{0}\right)\left(R_{G}(\mu, c)-R_{B}(\mu, c)\right) \\
& =\left(1-\mu_{0}\right)\left\{\left(r-(1-r) f_{B}(\mu, c)\right) \Delta W \Delta \operatorname{Pr}(\mu, c)-\left(1-f_{B}\right) c\right\},
\end{aligned}
$$

we see that $c$ enters through several channels, directly by raising the cost of high quality baskets and indirectly through $f_{B}(\mu, c)$ and $\Delta \operatorname{Pr}(\mu, c)$. There are three cases to consider.

Case 1. Suppose that $f_{B}=0$. Then $f_{B}$ remains constant at 0 in the neighborhood of $\mu^{*}$, and we have

$$
\bar{k}=\left(1-\mu_{0}\right)[(2 r-1) \Delta W \Delta \operatorname{Pr}-c],
$$

which is strictly decreasing in $c$, so the result follows.

Case 2. Suppose $f_{B} \in(0,1)$. Then $\Delta W \Delta \operatorname{Pr}=\frac{c}{(1-r)}$. Substituting into the above expression, we obtain $\bar{k}=\frac{2 r-1}{1-r} c \mu_{0}$, which is increasing in $c$. The result follows.

Case 3. Suppose that $f_{B}=1$. Then $f_{B}$ remains constant at 1 in the neighborhood of $\mu^{*}$, and we have

$$
\bar{k}=\left(1-\mu_{0}\right)(2 r-1) \Delta W \Delta \operatorname{Pr} .
$$

Because $\Delta \operatorname{Pr}$ depends on $c$ only through $f_{B}$, which is fixed at 1 , we have that $\bar{k}$ is independent of $c$.

\section{G. Proof of Lemma 6}

In light of $r>0.5$, the rating decisions (30) and (31) imply that $f_{G} \geq f_{B}$, and we consider the space of parameters that imply $f_{G}=1$. We first rule out the case of $f_{B}=0$. Suppose that $f_{B}=0$. The beliefs expressions (37) - (39) then imply that $\operatorname{Pr}_{G \mid G R}=\operatorname{Pr}_{G \mid B R}=1$ and $\operatorname{Pr}_{G \mid N R}=0$. It follows from the asset price expressions (34)-(36) that $P_{G R}=P_{B R}=W_{G}$ and $P_{N R}=W_{B}$. Substituting for these prices into (31), we see that it is optimal to rate poor quality assets as long as $\Delta W>c$, which holds by Assumption 2. This implies a contradiction.

The remaining cases are: (a) $f_{G}=f_{B}=1$ and (b) $f_{G}=1$ and $f_{B} \in(0,1)$. Both cases imply $\operatorname{Pr}_{G \mid N R}=0$ and therefore $P_{N R}=W_{B}$.

Consider case (a). For both types of assets to be rated, it must be the case that $P_{G R}+(1-r) P_{B R}>W_{B}+c$ and $(1-r) P_{G R}+r P_{B R}>W_{B}+c$. The latter condition is sufficient to ensure that both hold. Substituting for prices and beliefs in that condition and using $f_{B}=1$ in the resulting expression, we obtain

$$
\tilde{c}<\frac{\mu r(1-r)}{[\mu r+(1-\mu)(1-r)][\mu(1-r)+(1-\mu) r]} .
$$

Consider case (b). In this case, banks with poor quality assets are indifferent between rating and not rating, i.e.

$$
(1-r) P_{G R}+r P_{B R}-c=W_{B}
$$


Substituting for prices and beliefs into the above expression, we obtain

$$
\frac{(1-r) \mu r}{\mu r+(1-\mu) f_{B}(1-r)}+\frac{(1-r) \mu r}{\mu(1-r)+(1-\mu) f_{B} r}=\tilde{c} .
$$

The mixed strategy $f_{B}^{m i x}$ specified in the statement of this lemma is the positive root of the above expression. Setting $f_{B}^{m i x}>0$ simplifies to $\tilde{c}<1$, while setting $f_{B}^{m i x}<1$ simplifies to $\tilde{c}>\frac{\mu r(1-r)}{[\mu r+(1-\mu)(1-r)][\mu(1-r)+(1-\mu) r]}$.

Noting that $\frac{\mu r(1-r)}{[\mu r+(1-\mu)(1-r)][\mu(1-r)+(1-\mu) r]}$ equals 0 at $\mu=0$ and increases in $\mu$ in the interval $\mu \in(0,1)$, this lemma allows us to characterize the shape of $f_{B}(\mu)$ under mandatory ratings disclosure. For low $\mu$, $f_{B}(\mu) \in(0,1)$. As $\mu$ increases, $f_{B}$ switches to 1 and stays there. For all $\mu \in(0,1]$, we have $f_{B}>0$, which we know implies $f_{G}=1$, and therefore no additional restriction is needed to guarantee that $f_{G}=1$.

\section{H. Proof of Proposition 4}

To show that $\mu_{m d}^{*} \leq \mu^{*}$, it suffices to show that $H^{m d}(\mu) \leq H(\mu)$. Because $H(\mu)$ increases in $\bar{k}(\mu)=$ $\left(1-\mu_{0}\right) \Delta R(\mu)$, it suffices to show that

$$
\Delta R(\mu) \geq \Delta R^{m d}(\mu)
$$

We will drop the dependence of quantities and prices on $\mu$ for notational clarity.

Recall that in the benchmark economy,

$$
\begin{aligned}
\Delta R & =\left(r-(1-r) f_{B}\right)\left(P_{G R}-P_{B R}\right)-c\left(1-f_{B}\right), \\
P_{G R} & =\frac{\mu r}{\mu r+(1-\mu) f_{B}(1-r)} \Delta W+W_{B}, \\
P_{N R} & =\frac{\mu(1-r)}{\mu(1-r)+(1-\mu)\left[\left(1-f_{B}\right)+f_{B} r\right]} \Delta W+W_{B} .
\end{aligned}
$$

In the mandatory disclosure economy,

$$
\begin{aligned}
\Delta R^{m d} & =\left(r-(1-r) f_{B}^{m d}\right) P_{G R}^{m d}+\left(1-r-f_{B}^{m d} r\right) P_{B R}^{m d}-\left(1-f_{B}^{m d}\right) P_{N R}^{m d}-c\left(1-f_{B}^{m d}\right), \\
P_{G R}^{m d} & =\frac{\mu r}{\mu r+(1-\mu) f_{B}(1-r)} \Delta W+W_{B}, \\
P_{B R}^{m d} & =\frac{\mu(1-r)}{\mu(1-r)+(1-\mu) f_{B} r} \Delta W+W_{B}, \\
P_{N R}^{m d} & =W_{B} .
\end{aligned}
$$

Case 1. $f_{B}(\mu), f_{B}^{m d}(\mu)$ are both mixed.

In the benchmark economy,

$$
\triangle R=c \frac{2 r-1}{1-r},
$$

obtained by substituting for $\left(P_{G R}-P_{N R}\right)=\frac{c}{1-r}$ into $\Delta R$.

In the mandatory disclosure economy,

$$
\begin{aligned}
\triangle R^{m d} & =r P_{G R}^{m d}+(1-r) P_{B R}^{m d}-c-f_{B}^{m d}\left[(1-r) P_{G R}^{m d}+r P_{B R}^{m d}-c\right]-\left(1-f_{B}^{m d}\right) P_{N R}^{m d} \\
& =(2 r-1)\left(P_{G R}^{m d}-P_{B R}^{m d}\right) \\
& =(2 r-1) \Delta W\left[\frac{\tilde{c}}{(1-r)}-\frac{\mu}{\mu(1-r)+(1-\mu) f_{B}^{m d} r}\right]
\end{aligned}
$$

where we used $(1-r) P_{G R}^{m d}+r P_{B R}^{m d}-c=P_{N R}^{m d}$ in $\Delta R^{m d}$.

It follows that $\triangle R^{m d}<\triangle R$ because $\frac{\mu}{\mu(1-r)+(1-\mu) f_{B}^{m d} r}>0$.

Case 2. $f_{B}(\mu)=f_{B}^{m d}(\mu)=1$. 
In the benchmark economy,

$$
\begin{aligned}
\triangle R & =\left(r-(1-r) f_{B}\right)\left(\frac{\mu r}{\mu r+(1-\mu) f_{B}(1-r)}-\frac{\mu(1-r)}{\mu(1-r)+(1-\mu)\left(1-f_{B}(1-r)\right)}\right) \Delta W-c\left(1-f_{B}\right) \\
& =(2 r-1)\left(\frac{\mu r}{\mu r+(1-\mu)(1-r)}-\frac{\mu(1-r)}{\mu(1-r)+(1-\mu) r}\right) \Delta W,
\end{aligned}
$$

obtained by substituting for prices into $\triangle R$ and using $f_{B}=1$ in the resulting expression.

In the mandatory disclosure economy,

$$
\begin{aligned}
\triangle R^{m d} & =\left(r-(1-r) f_{B}\right) P_{G R}+\left(1-r-f_{B} r\right) P_{B R}-\left(1-f_{B}\right) P_{N R}-c\left(1-f_{B}\right) \\
& =(2 r-1)\left(P_{G R}-P_{B R}\right) \\
& =(2 r-1)\left[\frac{\mu r}{\mu r+(1-\mu)(1-r)}-\frac{\mu(1-r)}{\mu(1-r)+(1-\mu) r}\right] \Delta W,
\end{aligned}
$$

obtained by substituting for the relevant prices into $\Delta R^{m r}$ and using $f_{B}=1$ in the resulting expression.

We obtain that

$$
\triangle R=\triangle R^{m d}
$$

Case 3. $f_{B}(\mu)$ is mixed and $f_{B}^{m d}(\mu)=1$.

We already showed that $\triangle R=c \frac{2 r-1}{1-r}$ in the benchmark economy (case 1).

In the mandatory disclosure economy,

$$
\begin{aligned}
\Delta R^{m d} & =(2 r-1) \Delta W\left[\frac{\mu r}{\mu r+(1-\mu)(1-r)}-\frac{\mu(1-r)}{\mu(1-r)+(1-\mu) r}\right] \\
& =\frac{\Delta W(2 r-1)^{2} \mu(1-\mu)}{(r+\mu-2 r \mu)(1-(r+\mu-2 r \mu))},
\end{aligned}
$$

which is a symmetric inverted parabola centered at 0.5 .

If $c>(1-r)(2 r-1) \Delta W$ then the relevant range is $\mu \in\left(0, \mu_{3}\right)$ defined in Corollary 1 . In this range of $\mu$, $\triangle R^{m d}$ is maximized at 0.5 where it is valued at $(2 r-1)^{2} \Delta W$. It follows that

$$
\triangle R=\frac{c(2 r-1)}{(1-r)}>(2 r-1)^{2} \Delta W=\max _{\mu \in\left(0, \mu_{3}\right)} \triangle R^{m d} \geq \triangle R^{m d} .
$$

If instead $c \leq(1-r)(2 r-1) \Delta W$, then this case is in the range of $\mu \in\left(0, \mu_{1}\right) \cup\left(\mu_{2}, \mu_{3}\right)$ defined in Corollary 1. In this range, $\triangle R^{m d}$ is maximized at $\mu_{2}$ and $\mu_{3}$ where it is valued at $c \frac{2 r-1}{1-r}$. It follows that

$$
\triangle R^{m d} \leq \max _{\mu \in\left(0, \mu_{1}\right) \cup\left(\mu_{2}, \mu_{3}\right)} \triangle R^{m d}=c \frac{2 r-1}{1-r}=\triangle R .
$$




\section{References}

Allen, F., and D. Gale (2000): "Bubbles and Crisis," Economic Journal, 110(460), 236-255.

Andolfatto, D., and F. Martin (2013): "Information Disclosure and Exchange Media," Review of Economic Dynamics, 16(3), 527-539.

Asea, P., and B. Blomberg (1998): "Lending Cycles," Journal of Econometrics, 83(1-2), 89-128.

Beltran, D., L. Cordell, and C. Thomas (2017): "Asymmetric Information and the Death of ABS CDOs," Journal of Banking and Finance, 76, 1-14.

Benmelech, E., and J. Dlugosz (2009a): "The Alchemy of CDO Credit Ratings," Journal of Monetary Economics, 5, 617-634.

_ (2009b): "The Credit Rating Crisis," NBER Macroeconomics Annual, 24, 161-207.

Berger, A., And G. Udell (2004): "The Institutional Memory Hypothesis and the Procyclicality of Bank Lending Behavior," Journal of Financial Intermediation, 13(4), 458 - 495.

Blinder, A. (2007): "Six Fingers of Blame in the Mortgage Mess," New York Times, September 30.

Bolton, P., X. Freixas, and J. Shapiro (2012): "The Credit Ratings Game," The Journal of Finance, $67(1), 85-111$.

Bord, V., and J. Santos (2015): "Does Securitization of Corporate Loans Lead to Riskier Lending?," Journal of Money, Credit and Banking, 47, 415-444.

Boyd, J., and E. Prescott (1986): "Financial Intermediary - Coalitions," Journal of Economic Theory, $38(2), 211-232$.

Cohn, J., U. Rajan, and G. Strobl (2018): "Credit Ratings: Strategic Issuer Disclosure and Optimal Screening," Working Paper.

Cornaggia, J., K. Cornaggia, and J. Hund (2017): "Credit Ratings Across Asset Classes: A Long-Term Perspective," Review of Finance, 21(2), 465-509.

Damiano, E., H. Li, and W. Suen (2008): "Credible ratings," Theoretical Economics, 3(3), 325 - 365.

Dang, T., G. Gorton, and B. Holmstrom (2015): "Ignorance, Debt and Financial Crises," Working Paper.

DeMarzo, P. (2005): "The Pooling and Tranching of Securities: A Model of Informed Intermediation," $\underline{\text { Review of Financial Studies, }}$ 18(1).

Goldstein, I., and C. Huang (2018): "Credit Rating Inflation and Firms' Investments," Working Paper. 
Gorton, G. (2009): "Information, Liquidity, and the (Ongoing) Panic of 2007," American Economic Review, $99(2), 567-72$.

Gorton, G., and A. Metrick (2011): "Securitization," Handbook of the Economics of Finance.

Gorton, G., And G. Pennacchi (1995): "Banks and Loan Sales: Marketing Nonmarketable Assets," Journal of Monetary Economics, 35, 389-411.

Griffin, J., And D. Tang (2011): "Did Credit Rating Agencies Make Unbiased Assumptions on CDOs," American Economic Review: Papers \& Proceedings, 101(3), 125-130.

Hirshleifer, J. (1971): "The Private and Social Value of Information and the Reward to Inventive Activity," American Economic Review, 61(4), 561-574.

Holmstrom, B., and J. Tirole (1997): "Financial Intermediation, Loanable Funds, and the Real Sector," Quarterly Journal of Economics, 112(3), 663-691.

Kashyap, A., And N. Kovrijnykh (2016): "Who Should Pay for Credit Ratings and How?," The Review of Financial Studies, 29(2), 420-456.

Keys, B., A. Seru, and V. Vig (2012): "Lender Screening and the Role of Securitization: Evidence from Prime and Subprime Mortgage Markets," Review of Financial Studies, 25(7), 2071-2108.

Keys, B. J., T. Mukherjee, A. Seru, and V. Vig (2010): "Did Securitization Lead to Lax Screening? Evidence from Subprime Loans," Quarterly Journal of Economics, 125(1), 307-362.

Kurlat, P., and L. Veldkamp (2015): "Should We Regulate Financial Information?," Journal of Economic Theory, 158, 697-720.

Lown, C., And D. Morgan (2006): "The Credit Cycle and the Business Cycle: New Findings Using the Loan Officer Opinion Survey," Journal of Money, Credit and Banking, 38(6), 1575-1597.

Mathis, J., J. McAndrews, and J.-C. Rochet (2009): "Rating the raters: Are Reputation Concerns Powerful Enough to Discipline Rating Agencies?," Journal of Monetary Economics, 56(5), 657-674.

Mian, A., and A. Sufi (2009): "The Consequences of Mortgage Credit Expansion: Evidence from the 2007 Mortgage Crisis," Quarterly Journal of Economics, 124, 1449 - 1496.

Opp, C., M. Opp, and M. Harris (2013): "Rating agencies in the Face of Regulation," Journal of Financial Economics, 108(1), 46-61.

Parlour, C., and G. Plantin (2008): "Loan Sales and Relationship Banking," Journal of Finance, 63, $1291-1314$.

Povel, P., R. Singh, and A. Winton (2007): "Booms, Busts, and Fraud," The Review of Financial Studies, 20(4), 1219-1254. 
Purnanandam, A. (2011): "Originate-to-distribute Model and the Subprime Mortgage Crisis," Review of Financial Studies, 24(6), 1881-1915.

RaJan, R. (1994): "Why Bank Credit Policies Fluctuate: A Theory and Some Evidence," The Quarterly Journal of Economics, 109(2), 399-441.

Rajan, U., A. Seru, and V. Vig (2018): "The Failure of Models that Predict Failure: Distance, Incentives, and Defaults," Working Paper.

Sangiorgi, F., and C. Spatt (2017): "Opacity, Credit Rating Shopping and Asset Complexity: A Theory of Ratings Inflation," Management Science, 63(12), 3999-4446.

Shavell, S. (1994): "Acquisition and Disclosure of Information Prior to Sale," RAND Journal of Economics, 25(1), 20-36.

Skreta, V., and L. Veldkamp (2009): "Rating Shopping and Asset Complexity: A Theory of Ratings Inflation," Journal of Monetary Economics, 56(5), 678-695.

Stiglitz, J. (2007): "Houses of Cards," The Guardian, October 9. 